\title{
REVIEW
}

\section{Sexual production of corals for reef restoration in the Anthropocene}

\author{
Carly J. Randall ${ }^{1, *}$, Andrew P. Negri ${ }^{1}$, Kate M. Quigley ${ }^{1}$, Taryn Foster ${ }^{2}$, \\ Gerard F. Ricardo ${ }^{1}$, Nicole S. Webster ${ }^{1,3}$, Line K. Bay ${ }^{1}$, Peter L. Harrison ${ }^{4}$, Russ C. \\ Babcock $^{5}$, Andrew J. Heyward ${ }^{2}$ \\ ${ }^{1}$ Australian Institute of Marine Science, PMB 3, Townsville, QLD 4810, Australia \\ ${ }^{2}$ Australian Institute of Marine Science, Indian Ocean Marine Research Centre, University of Western Australia, Crawley, \\ WA 6009, Australia \\ ${ }^{3}$ Australian Centre for Ecogenomics, University of Queensland, Brisbane, QLD 4072, Australia \\ ${ }^{4}$ Marine Ecology Research Centre, Southern Cross University, Lismore, NSW 2480, Australia \\ ${ }^{5}$ Oceans and Atmosphere, Commonwealth Scientific and Industrial Research Organisation, St Lucia, QLD 4072, Australia
}

\begin{abstract}
Coral-reef ecosystems are experiencing frequent and severe disturbance events that are reducing global coral abundance and potentially overwhelming the natural capacity for reefs to recover. While mitigation strategies for climate warming and other anthropogenic disturbances are implemented, coral restoration programmes are being established worldwide as an additional conservation measure to minimise coral loss and enhance coral recovery. Current restoration efforts predominantly rely on asexually produced coral fragments - a process with inherent practical constraints on the genetic diversity conserved and the spatial scale achieved. Because the resilience of coral communities has hitherto relied on regular renewal with natural recruits, the scaling-up of restoration programmes would benefit from greater use of sexually produced corals, which is an approach that is gaining momentum. Here we review the present state of knowledge of scleractinian coral sexual reproduction in the context of reef restoration, with a focus on broadcast-spawning corals. We identify key knowledge gaps and bottlenecks that currently constrain the sexual production of corals and consider the feasibility of using sexually produced corals for scaling-up restoration to the reef- and reef-system scales.
\end{abstract}

KEY WORDS: Coral reproduction - Sexual reproduction - Coral restoration - Gametogenesis · Embryogenesis $\cdot$ Spawning $\cdot$ Settlement $\cdot$ Climate change

\section{INTRODUCTION}

Up to half of the world's tropical corals have been lost in the last $50 \mathrm{yr}$ (Pandolfi et al. 2003, Wilkinson 2008, Burke et al. 2011, De'ath et al. 2012, Hughes et al. 2017, 2018), and over one-third of scleractinian coral species are now at increased risk of extinction (Carpenter et al. 2008). Three pan-tropical mass-

\footnotetext{
${ }^{*}$ Corresponding author: c.randall@aims.gov.au
}

bleaching events occurred in the last 4 decadesincluding unprecedented back-to-back bleaching and mortality events on the Great Barrier Reef (GBR) in 2016 and 2017 - collectively signalling an acceleration in global reef decline (Sweet \& Brown 2016, Hughes et al. 2018). The increasing frequency, intensity, and spatial scale of these thermal-stress events no longer allows sufficient time between disturbances

(C) The authors and the Australian Institute of Marine Science 2020. Open Access under Creative Commons by Attribution Licence. Use, distribution and reproduction are unrestricted. Authors and original publication must be credited. 
for coral communities to recover to their pre-disturbance cover and composition (Osborne et al. 2017, Hughes et al. 2018, Lough et al. 2018, Ortiz et al. 2018). Furthermore, coral-bleaching events are no longer constrained to years with extreme El NiñoSouthern Oscillation (ENSO) conditions (Hughes et al. 2018), and are affecting reefs regardless of conservation status and management regime (Selig et al. 2012), leading to calls for additional action, including direct restoration interventions (see Anthony et al. 2017, van Oppen et al. 2017). At present, active coral restoration is spatially limited (e.g. Hein et al. 2017), and coral restoration programmes targeting entire reefs and reef systems will require new approaches to re-establish ecosystem functions at ecologically relevant scales.

Most coral restoration programmes to date have leveraged the clonal structure of coral colonies and utilised 'coral gardening' techniques, whereby corals are fragmented or microfragmented (asexually) and outplanted onto degraded reefs or artificial reef structures (Bowden-Kerby 2003, Rinkevich 2005, 2008, Forsman et al. 2006, 2015, Shaish et al. 2010, Johnson et al. 2011, Young et al. 2012, Lirman \& Schopmeyer 2016). An alternative, and increasingly advocated approach, is to generate and deploy sexually produced corals (e.g. Heyward et al. 2002, Edwards \& Gomez 2007, Harrison 2011, Nakamura et al. 2011, Guest et al. 2014, Omori \& Iwao 2014, Chamberland et al. 2015, 2017, Harrison et al. 2016, dela Cruz \& Harrison 2017, Pollock et al. 2017, Omori 2019, see also www. secore.org).

Future restoration approaches involving the mass production of corals are likely to benefit from combining traditional asexual propagation methods with advances in the sexual production of corals. Firstly, collecting sexual propagules while leaving adult colonies on the reef is a more ecologically sustainable approach. Secondly, the use of sexual propagules from spawning events is arguably the most cost-effective and feasible way to produce the large numbers of corals required for restoration (Edwards 2010, Doropoulos et al. 2019). Finally, and perhaps most importantly, approaches using sexual reproduction promote genetic diversity, which is central to species conservation (Baums 2008, van Oppen et al. 2015, 2017). The sexual generation of corals also enables selective breeding of individuals with potentially advantageous traits, such as temperature tolerance (van Oppen et al. 2017), which may already exist in bleaching survivors and populations from naturally extreme or marginal environments (e.g. Barshis et al. 2013, Howells et al. 2016a). Given the rapid and accelerating rates of en- vironmental change associated with increasing greenhouse-gas emissions, it is essential to maintain and potentially enhance the acclimatisation and adaptation potential supported by high genetic diversity within existing coral populations. Consequently, restoration programmes that produce corals sexually have started to gain momentum over the last decade.

In this review, we summarise the current state of knowledge of sexual reproduction in scleractinian corals within the context of reef restoration, with a focus on broadcast spawning, which is both the dominant mode of sexual reproduction and currently is more amenable to large-scale larval culture than the collection of planulae from brooding species. Additional information from studies of brooding corals is included where relevant. We highlight key knowledge gaps and bottlenecks in the coral life cycle where human intervention may optimise or accelerate processes for application in reef restoration. We also summarise key knowledge needs to guide research in the broader coral restoration community, and consider the feasibility of recovering the structure and function of degraded coral reefs through interventions with sexually produced corals.

\section{THE CORAL LIFE CYCLE}

Scleractinian corals have a biphasic life cycle composed of a dominant sessile, benthic polyp phase and a motile planula larval phase (our Fig. 1; Harrison \& Wallace 1990, Richmond \& Hunter 1990, Harrison 2011). Polyps form the basic unit of a coral colony, and the polyp phase is dominated by somatic growth and asexual budding that creates new and genetically identical polyps. Once a coral colony reaches an adequate size and age, a cycle of sexual reproduction commences (Fig. 1).

The modes of sexual reproduction have been identified for approximately half of the estimated 900 extant species of hermatypic scleractinians (Veron 2000), and 4 general patterns have emerged: (1) hermaphroditic broadcast spawning; (2) hermaphroditic brooding; (3) gonochoric broadcast spawning; and (4) gonochoric brooding (Fadlallah 1983, Harrison 1985, 2011, Richmond \& Hunter 1990, Baird et al. 2009, Madin et al. 2016). While most corals with known reproductive patterns follow one of these strategies, some species do not conform to the typical dichotomies (i.e. brooding vs. spawning and hermaphroditic vs. gonochoric; Harrison 2011, Guest et al. 2012), and it is likely that the diversity of recorded reproductive patterns will continue to increase as more taxa are studied. 


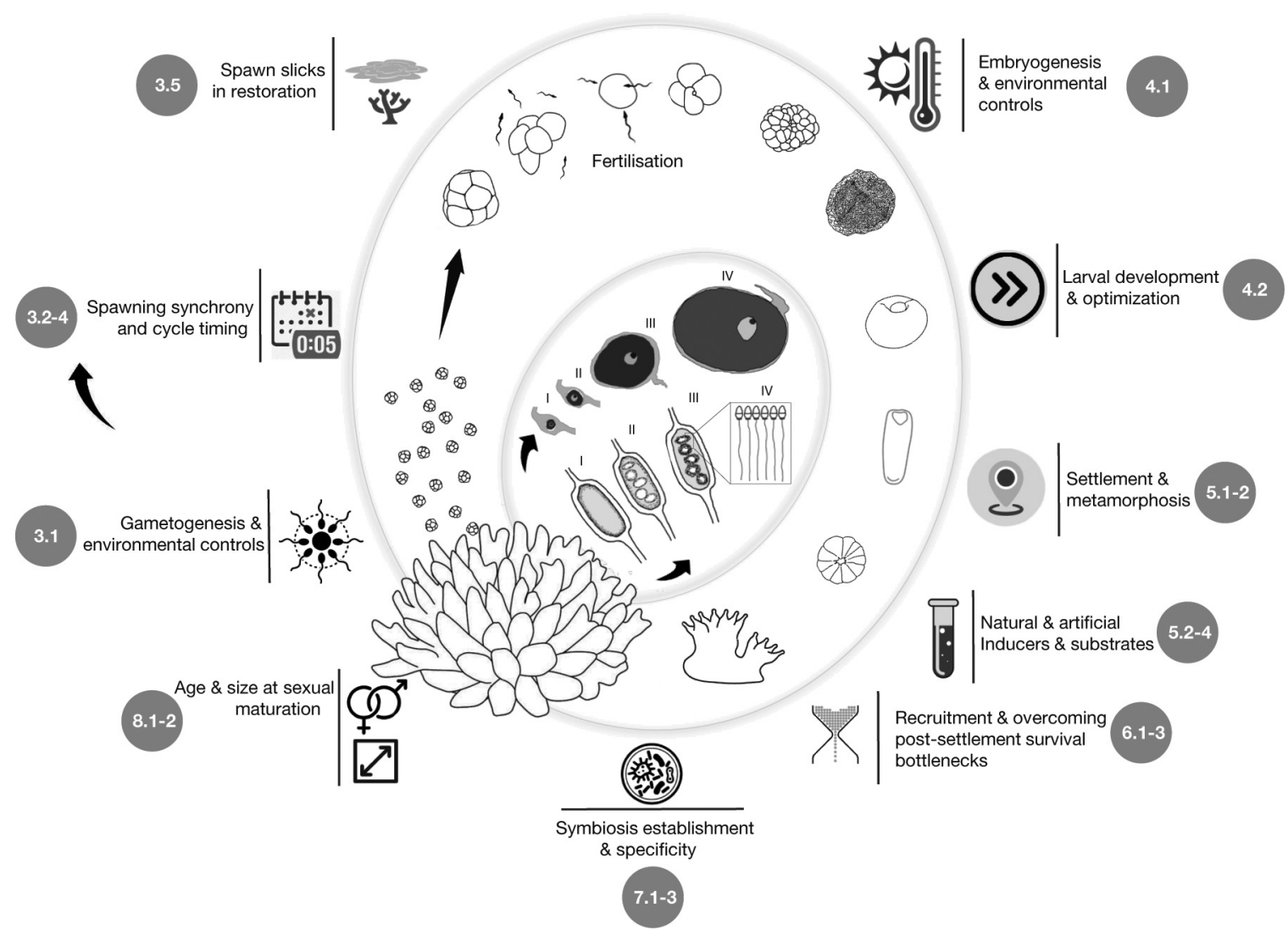

Fig. 1. Stages of broadcast-spawning coral life cycle (after Jones et al. 2015), with stages of gametogenesis in the centre (after Vargas-Ángel et al. 2006). Text sections of the present paper are indicated by the numbers in the filled grey circles, and key restoration research priorities for each developmental stage are indicated with icons as defined in Table 2. Gametes develop within or attached to mesenteries that contain oocytes and/or spermatocytes and progress through 4 stages, over several months or more (I-IV; e.g. Szmant-Froelich et al. 1980, Szmant-Froelich 1985, Harrison \& Wallace 1990, Glynn et al. 1991, Vermeij et al. 2004, Madsen et al. 2014). Oocytes (top row of inner cycle) begin as enlarging interstitial cells adjacent to, or within, the mesenterial mesoglea (Stage I; Madsen et al. 2014), and slowly accumulate cytoplasm around the nucleus (Stage II). Over time, oocytes increase in size, and yolk forms around the nucleus (vitellogenesis, Stage III), with final maturation (Stage IV) occurring as the cortical layer and vitelline membrane are complete, as the yolk granulates and the egg becomes visibly pigmented in many species, and finally as the nucleus moves toward one side of the egg (Stage IV). Sperm development (bottom row of inner cycle) begins with the clustering of spermatogonia adjacent to, or within, the mesoglea (Stage I), which is followed by meiosis and the development of distinct spermatocytes with large nuclei in Stage II. The number of spermatocytes and spermatids within the spermary increases during Stage III as meiosis continues, and they become peripherally arranged with prominent central lacunae. In Stage IV, spermatids have little cytoplasm, develop a flagellum, and arrange themselves in bouquet arrays within the spermaries

Gonochoric species have separate sexes, while hermaphroditic corals develop both eggs and sperm within polyps or colonies. Most hermaphroditic corals are simultaneous hermaphrodites, while some are sequential (Harrison 2011), and a few exhibit bidirectional sex change (i.e. Loya et al. 2009, EyalShaham et al. 2019). Broadcast-spawning corals release gametes into the water column for external fertilisation and larval development. Brooders typically undergo internal fertilisation and release welldeveloped planula larvae, although some species produce asexually brooded larvae (Harrison 2011). Over $80 \%$ of species whose reproductive modes are known spawn gametes for external fertilisation (Baird et al. 2009, Harrison 2011).

\section{GAMETOGENESIS, SPAWNING, AND REPRO- DUCTIVE SYNCHRONY}

Coral reproductive cycles are aligned with environmental conditions that improve survival and fitness. Environmental conditions can regulate reproductive cycles in 2 ways: as ultimate factors, which exert evolutionary selective pressures to maximise reproductive success (Babcock et al. 1986, Harrison 
\& Wallace 1990, Oliver et al. 1998), and as proximate factors, which cue and synchronise cycles. Ultimate factors include seasonal temperature cycles that may optimise physiological performance (Babcock et al. 1986, Keith et al. 2016), wind speeds (van Woesik 2010, Heyward \& Negri 2012) and tidal phases (Babcock et al. 1986, 1994) that may maximise fertilisation success and dispersal, and diurnal cycles that may allow for predator avoidance (Harrison et al. 1984). In the context of coral restoration, we are unlikely to be able to manipulate ultimate factors, and doing so is risky and may decrease fitness. Therefore, we focus here on proximate factors that act mechanistically, which are more amenable to experimental manipulation, and that are most relevant to restoration.

Proximate factors that synchronise gametogenic and spawning cycles (Fig. 1) are thought to be regulated by a hierarchy of exogenous environmental cues (e.g. annual, seasonal, lunar, and daily, as detailed in the following sections) that interact with endogenous biorhythms at successively finer timescales to optimise reproductive success (Harrison \& Wallace 1990, Hoadley et al. 2016). There is a rapidly growing understanding of the endogenous and molecular mechanisms that underpin reproductive cycles and synchronisation (e.g. Sorek et al. 2014, Kaniewska et al. 2015, Hoadley et al. 2016), which shows great promise for our ability to manipulate gametogenesis and spawning for restoration. However, it is critical that such manipulations retain the reproductive characteristics of wild populations to allow for interbreeding with existing populations after deployment.

\subsection{Annual and seasonal controls of gametogenesis}

For most broadcast spawners, gametogenesis follows an annual cycle; oogenesis takes place slowly, over multiple months (4-12 mo), while spermatogenesis occurs more quickly (1-8 mo), with sperm maturation coinciding with the final stages of oogenesis, usually a few days or weeks prior to an annualspawning event (our Fig. 1; Wallace 1985, Szmant 1986, Harrison \& Wallace 1990, Vermeij et al. 2004, Vargas-Ángel et al. 2006, Chin et al. 2014). However, multiple gametogenic cycles per year have been described in some coral populations (e.g. Stobart et al. 1992, Penland et al. 2004, Mangubhai \& Harrison 2008a), and many brooding species have several overlapping gametogenic cycles each year (Kojis 1986, Szmant 1986, Harrison \& Wallace 1990, Foster
\& Gilmour 2018), with some releasing larvae on a daily basis (Nietzer et al. 2018).

Temperature has long been considered an important factor governing reproductive seasonality and often is correlated with gametogenic cycles in broadcast spawners and some brooders (Shlesinger \& Loya 1985, Babcock et al. 1986, Kojis 1986, Hayashibara et al. 1993, Vargas-Ángel et al. 2006, Nozawa 2012, Keith et al. 2016). Oogenesis usually commences asynchronously during cooler periods in autumn or winter months (Wallace 1985, Szmant 1986, Harrison \& Wallace 1990, Vargas-Ángel et al. 2006); then, as seawater temperatures rise rapidly in mid-spring, oocyte diameter increases and oocytes gradually develop from Stage I through Stage IV, culminating in synchronised maturation (Stage IV) during periods of warm seawater temperatures (our Fig. 1, inner cycle; Wallace 1985, Willis et al. 1985, Szmant 1986, Vargas-Ángel et al. 2006, Madsen et al. 2014, Keith et al. 2016). While temperature clearly affects the rates of physiological processes in corals, it likely plays a secondary role in determining the timing of spawning, either by affecting growth and final maturation directly (Nozawa 2012) or through interactions between endogenous clock mechanisms (e.g. Kaniewska et al. 2015) and temperature.

Solar insolation is another important cue that synchronises gametogenesis, particularly for equatorial corals that experience a small annual range in seawater temperatures (Penland et al. 2004, van Woesik et al. 2006, Brady et al. 2009). Light is thought to entrain oscillations of a molecular clock ( $24 \mathrm{~h}$ periodicity) through 2 interacting transcription/translation feedbacks that form an endogenous rhythm, the 'speed' of which is in synchrony with seasonal changes in day length (Hoadley et al. 2016). Light acts as a proximate cue for reproduction, but is also a fundamental energy source driving reproductive effort. Reduction in solar insolation with increasing latitude or water depth may constrain reproductive effort, resulting in protracted gamete development (i.e. 'slower speeds') and lower overall fecundity (Kojis \& Quinn 1984, Harii et al. 2001, Feldman et al. 2018, Shlesinger et al. 2018).

While spawning usually occurs once per year in a synchronous-spawning event, it can also be protracted, occurring as sequential events over several months and seasons (Shlesinger \& Loya 1985, Heyward 1987, Hayashibara et al. 1993, Penland et al. 2004, Mangubhai \& Harrison 2008b, Fogarty et al. 2012, Bouwmeester et al. 2015). Biannual spawning within coral populations has been observed in Western Australia (Gilmour et al. 2009, 2016), and split-spawning-a 
form of asynchrony that occurs somewhat predictably every $2-3$ yr-happens either when the same colony spawns over 2 or 3 consecutive months, or when different colonies from the same population spawn on successive lunar cycles (Willis et al. 1985, Mangubhai \& Harrison 2008b, Baird et al. 2009, 2012, Foster et al. 2015, 2018, Gilmour et al. 2016).

\subsection{Lunar controls of spawning}

Remarkably, gamete release within species can be synchronised to within minutes, and often is restricted to a single night of the year. Within seasons, spawning is correlated with the lunar cycle and is likely cued directly by moonlight detected through photoreceptors (possibly cryptochromes or opsins, see Hoadley et al. 2016) that sense moonlight intensity (Levy et al. 2007, Kaniewska et al. 2015, but see Linden et al. 2018). Some brooding species may use similar processes to coordinate planulae release, whereas other brooders do not exhibit lunar periodicity in planulation (Jokiel et al. 1985, Vermeij et al. 2003, Zakai et al. 2006, Linden et al. 2018, Nietzer et al. 2018). No data are available on photosensitivity of cnidarian cryptochromes; however, they may form part of the circadian clock rather than serve as photosensors (Hoadley et al. 2016). Manipulating the day of spawning or planulation based on offset artificial moonlight cycles could be used to distribute coral production in aquaculture facilities throughout the month, reducing bottlenecks in culture processes that could occur when relying on single monthly spawnings. Manipulating lunar and seasonal temperature and light cycles to split spawning across months also could potentially increase coral production in controlled aquaculture systems.

\subsection{Diel controls of spawning}

While several species have been observed to spawn during daylight (e.g. Mangubhai et al. 2007, EyalShaham et al. 2019), the final and shortest temporal cue for the majority of spawning species is the time after sunset on the night of spawning; conspecifics consistently spawn a certain number of minutes to hours after sunset (Willis et al. 1985, Babcock et al. 1986, Vize 2006), and similar diel cycles of planulae release are evident among some brooding species (Jokiel et al. 1985, Fan et al. 2006). This timing can persist even following artificial induction of gamete release (Hayashibara et al. 2004) and when diel cycles are off- set to manipulate the timing of spawning (Babcock 1984). This behaviour is directly controlled by local photoperiod and does not appear to be entrained by a biological clock (Brady et al. 2009).

\subsection{Predicting and controlling gametogenesis and spawning for restoration}

Identifying the underlying drivers of synchronous spawning among more taxa will enable the efficient and reliable production of a greater diversity of coral species for restoration. For example, more reliable information about spawning cycles for daytime or dawn spawners (e.g. Bronstein \& Loya 2011, EyalShaham et al. 2019) would allow production effort to be spread across species throughout the day and night, and identification of multiple spawning events within a population (e.g. Stobart et al. 1992) could provide additional opportunities throughout the year for spawn collection. Furthermore, reliably obtaining spawned gametes from other important coral taxa (beyond reliance on acroporid and merulinid species) is important to retain functional diversity of restored ecosystems.

Manipulation of endogenous rhythms and optimised aquaculture conditions may underpin future hatchery-style production of corals. Practitioners could (1) maintain multiple populations on off-set annual cycles to produce gametes several times per year, (2) accelerate gametogenesis so that 1 population can be spawned several times per year, and (3) control the hour of spawning to spread effort throughout the day. Research has already begun to test the feasibility of some of these options. Firstly, by artificially mimicking seasonal and daily insolation cycles, lunar-irradiance cycles, and seasonal temperature fluctuations, Craggs et al. (2017) replicated natural gametogenic cycles in GBR corals that were transported and maintained for $>1 \mathrm{yr}$ in an aquarium in the UK. This is a first step in maintaining synchronously spawning populations in artificially controlled environments. Secondly, maintaining optimal light intensity to support photosynthesis and providing additional food sources for corals ex situ may partly overcome nutrient limitations for gametogenesis, allowing for multiple gametogenic cycles per year (e.g. Szmant-Froelich et al. 1980).

There may be potential trade-offs, however, between increased gamete production and other vital processes such as somatic-tissue growth, calcification, and immune responses (Harrison \& Wallace 1990). Furthermore, the quality and viability of gametes re- 
sulting from nutrient enrichment may be inferior to those produced under natural conditions, and thus further investigation is needed prior to implementation in any restoration programme (e.g. Ward \& Harrison 2000). Lastly, the long-term effects of out-of-season-spawned corals on future spawning synchrony and fitness are not known and must be investigated.

\subsection{Capturing spawn slicks for restoration}

Synchronously spawning corals, with colony fecundities reaching $10^{6} \mathrm{~m}^{-2}$ (e.g. Álvarez-Noriega et al. 2016, Howells et al. 2016b), may release billions of eggs and sperm per hectare of reef. Under calm conditions, these positively buoyant eggs can form highly concentrated and species-rich surface slicks (our Fig. 2a; Butler 1980, Oliver \& Willis 1987), and if the gametes are healthy, could provide a natural source of sexually produced propagules for restoration (Kawaguti 1940, Heyward et al. 1999, Omori \& Fujiwara 2004, Harrison et al. 2016).

Spawn slicks are generally pink or white in colour and can be observed as discrete patches or narrow strips on the sea surface extending several kilometres from a reef (Butler 1980, Oliver \& Willis 1987). The size and location, the species composition, the viability, and the longevity of a slick are all closely tied both to oceanographic and environmental conditions and to coral composition and abundance. When and where slicks will form, and how long they persist, is controlled by surface oceanographic features, such as eddies or fronts between water bodies (Wolanski \& Hamner 1988, Jones et al. 2006), and is dependent on wind speed. Wind speeds between 2 and $4 \mathrm{~m} \mathrm{~s}^{-1}$ are associated with the highest probability of slick formation (Romano \& Marquet 1991, van Woesik 2010), while slicks are unlikely to form at wind speeds above 6-7 $\mathrm{m} \mathrm{s}^{-1}$ (Romano 1996). Although coral spawning often occurs during calm periods (van Woesik 2010), weather monitoring over a decade at selected reefs on the GBR showed that wind speed exceeded $5 \mathrm{~m}$ $\mathrm{s}^{-1}$ for $\sim 50 \%$ of major spawning events (Heyward \& Negri 2012). Similarly, in the Philippines, slight differences in local turbulence from year to year have influenced the extent of slick formation and their speed of dispersal (Jamodiong et al.
2018). Therefore, local meteorological and oceanographic conditions during coral spawning have important roles in predicting slick formation at a given reef.

The species composition and viability of the slick are closely tied to the abundance of adult corals on the reef from the most fecund spawning families, such as Acroporidae and Merulinidae. The biological and physical attributes of propagules, including oocyte diameter, buoyancy, and developmental rate, also vary by species and consequently affect the propensity of each species to end up in slicks. A slick sample from the GBR, for example, contained earlystage larvae, in a size range mostly between 200 and $800 \mu \mathrm{m}$, with modal peaks around 400 and $550 \mu \mathrm{m}$ and a mean diameter of $484 \mu \mathrm{m}$ (Fig. 2b,c), indicating a diversity of species. Extrapolation from these sizes to a calculation of packed cell volume suggests that a dense surface slick just $1 \mathrm{~mm}$ thick could contain several million eggs, embryos, or larvae per square metre, although viability within slicks can be highly variable (Oliver \& Willis 1987). Poor viability in some slicks may be caused by rainfall creating low-salinity stress (Harrison et al. 1984, Richmond 1993) or anoxic conditions in the surface layer from microbial decomposition of spawn, caused by either low fertilisation success or sequential days of spawning (Simpson et

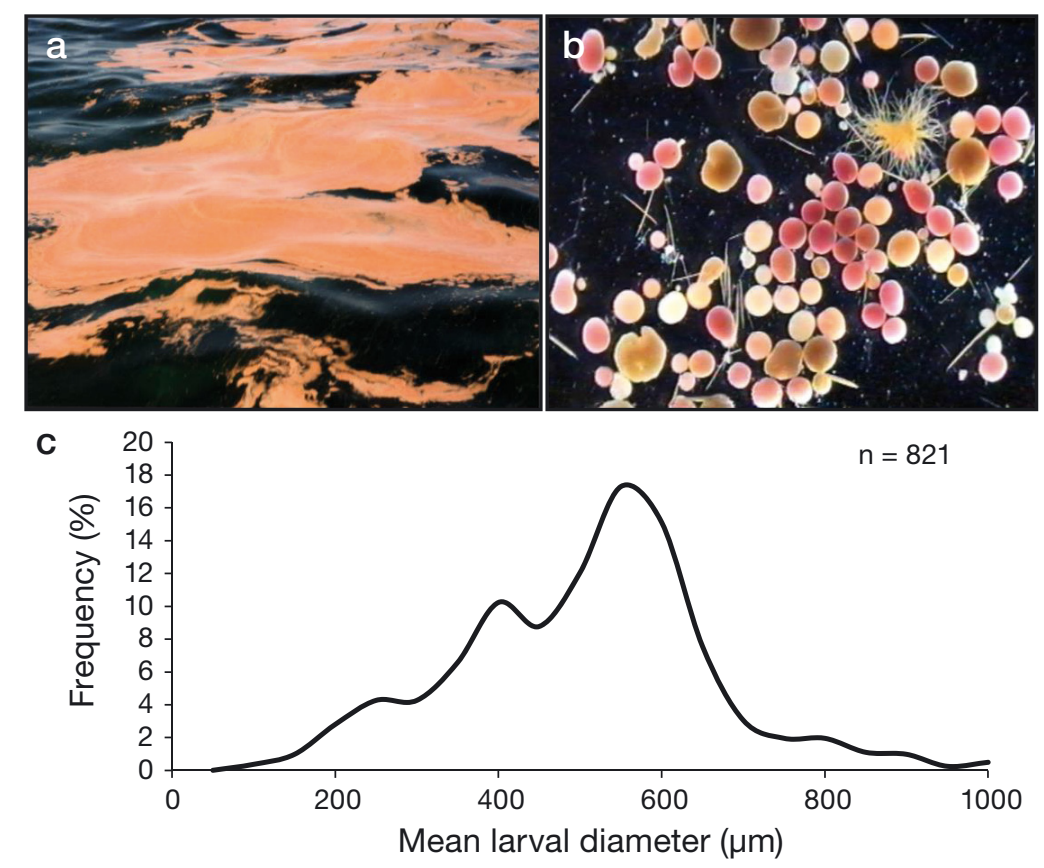

Fig. 2. (a) Multi-species coral surface slick at Lizard Island, at 07:00 h, the morning after spawning. (b) Photomicrograph of a sample from the surface slick in (a), showing various coral embryos and larvae and other flotsam. (c) Coral larval size-frequency distribution measured from the slick shown in $(a, b)$. ' $n$ ' in (c) indicates the number of larvae measured to estimate the sizefrequency distribution. Photos: A. Heyward 
al. 1993, Guillemette et al. 2018). Because the formation, size, and viability of slicks are influenced by the abundance of adult colonies, the accessibility of coral slicks for restoration may diminish in parallel with a decline in coral abundance.

Spawn slicks could be utilised in restoration by: (1) holding a slick above a target reef to mimic natural retention and increase recruitment (e.g. Golbuu et al. 2012, Harrison et al. 2016); (2) collecting and transporting larvae from a slick to a recruitment-limited reef location for release (Heyward et al. 1999, 2002, dela Cruz \& Harrison 2017, Doropoulos et al. 2019); or (3) collecting and settling larvae from a slick onto artificial substrates for grow-out and deployment (e.g. Chamberland et al. 2017). Efforts to collect and deliver captive larvae back to the reef and manipulate larval settlement have so far utilised floating ponds and hoses (Heyward et al. 2002, Omori et al. 2004), mesh enclosures (dela Cruz \& Harrison 2017), tents (Edwards et al. 2015), plastic bags (Suzuki et al. 2012), foam ring-seeder devices (Cooper et al. 2014), and Perspex boxes (Quigley et al. 2018b). However, coral restoration programmes targeting entire reefs and reef systems would need to implement such methods at much larger scales than have previously been attempted (Doropoulos et al. 2019).

In early trials, harvested wild slicks produced competent larvae in Western Australia (Heyward et al. 2002) and Okinawa (Omori et al. 2004). Those studies, and subsequent restoration efforts using captivespawned larvae in Palau (Edwards et al. 2015) and the Philippines (dela Cruz \& Harrison 2017), demonstrated enhanced settlement rates through increased larval supply. Nonetheless, increased settlement rates on artificial surfaces did not elevate the numbers of surviving 1 yr old corals above that observed in adjacent areas with natural recruitment in Palau (Edwards et al. 2015). In contrast, larval enhancement on 4 replicate $24 \mathrm{~m}^{2}$ degraded reef plots with low natural recruitment in the Philippines increased recruitment rates of Acropora tenuis compared with reference plots, and re-established a breeding population within $3 \mathrm{yr}$ (dela Cruz \& Harrison 2017). These examples demonstrate that a positive outcome from larval restoration is possible in some situations, but the cost-effectiveness and scalability of this approach remain challenging.

There is a limited period for the capture of a surface slick with concentrated and viable embryos and larvae. Coral embryos are structurally fragile during the first hours of development (Heyward \& Negri 2012) but become more robust after gastrulation. Consequently, careful isolation and containment of a slick may be feasible in the hour or 2 immediately after spawning, prior to cleavage (which may be protracted for multi-species slicks), but otherwise is best delayed until the cohort is at least $24 \mathrm{~h}$ old (Omori \& Fujiwara 2004). Subsequently, a period of days (but generally not weeks) is available for culture and transport. Extended transit times risk larval settlement during transport, particularly for cultures of brooded larvae, which are usually released at an advanced larval stage and are competent to settle quickly after release. Therefore, slick harvesting should consider larval viability and concentration at or near the surface, bearing in mind early embryo fragility and changes to larval distribution in the water column during development (Section 4.1). These trade-offs provide several technical challenges for the future large-scale use of slicks for coral restoration.

\section{EMBRYOGENESIS AND LARVAL DEVELOPMENT}

Embryogenesis and larval development are among the most sensitive processes in the coral life cycle (Figs. 1 \& 3). Understanding where and when these processes take place, the risks and sensitivities associated with these stages, and their environmental drivers will allow culture conditions to be optimised for the ex situ production of corals.

\subsection{Environmental controls on embryogenesis and larval development}

Early embryogenesis (our Fig. $3 \mathrm{f}-\mathrm{h}_{\text {; }}$ first cleavage through blastula) usually occurs overnight at the sea surface (Babcock \& Heyward 1986, Hayashibara et al. 1997, Ball et al. 2002, Okubo \& Motokawa 2007, Okubo et al. 2013, 2017). The lipid-rich embryos of most species (Arai et al. 1993) are positively buoyant and passively transported, while cilia develop on the outer surface, leading to 'rotary' swimming. The timing of the onset of rotary swimming varies across species but can occur as early as $12 \mathrm{~h}$ (e.g. Pavona decussata) or as late as $3 \mathrm{~d}$ (e.g. Pseudosiderastrea spp.) after fertilisation (Okubo et al. 2013). Directional swimming of the larvae is achieved hours to days after rotary swimming, when they begin exhibiting phototactic responses and become capable of adjusting their positions in the water column (our Fig. 3j, $\mathrm{k}_{\text {; }}$ Lewis 1974, Harrison \& Wallace 1990). The timing of larval competency for settlement also varies across species (reviewed in Jones et al. 2015) and can occur 
as early as $24 \mathrm{~h}$ after spawning (e.g. Fungia fungites) or can require a week or more of larval development (e.g. Acropora austera).

Environmental factors that affect fertilisation success and can cause embryonic abnormalities include elevated inorganic nutrient concentrations (reviewed in Fabricius et al. 2005, Humphrey et al. 2008, Lam et al. 2015, Richmond et al. 2018), $p \mathrm{CO}_{2}$ (Albright 2011, Albright \& Mason 2013), sediments (reviewed in Jones et al. 2015), and pollutants (reviewed in Hudspith et al. 2017). Rates of embryogenesis are also temperature-dependent; warm temperatures have been shown to accelerate development in several species, including acroporids and mussids (Bassim et al. 2002, Bassim \& Sammarco 2003, Negri et al. 2007, Randall \& Szmant 2009a, Heyward \& Negri 2010, Chua et al. 2013, Graham et al. 2017). Warmer ocean temperatures can also reduce fertilisation success (Negri et al. 2007, Albright \& Mason 2013) and increase the likelihood of embryonic abnormalities, leading to increased mortality (Bassim et al. 2002, Bassim \& Sammarco 2003, Negri et al. 2007, Randall \& Szmant 2009a,b). In a study of Acropora palmata, a $4^{\circ} \mathrm{C}$ increase in temperature decreased larval survival by $\sim 60 \%$, with most losses occurring during the process of gastrulation (Randall \& Szmant 2009a).

Coral embryos lack the protective external membrane of some other metazoans; hence, early embryonic stages are fragile and readily fragment into smaller groups of cells (Heyward \& Negri 2012). During windy and turbulent conditions, for example, early morulae (2-16-cell stages; Fig. 3m) can fragment and then continue cleaving, eventually developing into proportionally smaller larval clones, sometimes oneeighth the normal size (Heyward \& Negri 2012). The deliberate fragmentation of early embryos to generate smaller larvae in culture may increase larval numbers and compress the larval competency period, as smaller larvae generally reach competency sooner (Figueiredo et al. 2013). However, larger fragments (blastomeres) are more likely to survive, and the resulting small recruits may be disadvantaged, as the time required to grow to size-escape thresholds may be longer (Raymundo \& Maypa 2004, Doropoulos et al. 2012b). Furthermore, only fragments with animal hemispheres can develop into primary polyps (Okubo et al. 2017).

\subsection{Optimising embryogenesis and larval development for restoration}

In culture, direct handling of embryos should be minimised, and mass cultures should initially have no aeration and slow water movement for the first 18$24 \mathrm{~h}$, unless deliberately generating small embryos (Edwards 2010, Omori \& Iwao 2014, Pollock et al. 2017). Aeration and water flow can be increased once embryos reach the gastrula stage (our Fig. 3i) 12-24 h post-fertilisation (Okubo et al. 2013).

Exposure to elevated-temperature conditions during early-life histories is a potential tool for accelerating development (Nozawa \& Harrison 2000, 2007, Randall Szmant 2009a, Heyward \& Negri 2010) and enhancing the thermal tolerance of restored corals (Putnam \& Gates 2015, van Oppen et al. 2015, 2017). Nonetheless, possible benefits of accelerated rates of development and stress-hardening may be countered by lower fertilisation rates, higher rates of developmental abnormalities, disease, mortality, and downstream consequences on general culture health. Thermal tolerance selection through stresshardening of coral larvae, and its role in long-term acclimatisation, have not yet been quantified, and thus constitute critical research priorities.

\section{SETTLEMENT AND METAMORPHOSIS}

The successful recruitment of corals includes both settlement (Section 5) and post-settlement survival (Section 6), and reef restoration would benefit from the optimisation of both processes.

\subsection{Larval sensory systems and the processes of settlement and metamorphosis}

The transition from a motile planula larva to a sessile polyp (i.e. 'settlement') is a multi-stage process that includes selection of a settlement substrate, followed by attachment to that substrate, metamorphosis from larva to polyp, and finally acquisition of photosymbionts (Section 7) for those species that acquire them from the environment (Harrison \& Wallace 1990). Although planktonic larvae are transported by ocean currents, they can vertically modulate their position in the water column (Tay et al. 2011), which increases their likelihood of intercepting reef substrate (Raimondi \& Morse 2000, Szmant \& Meadows 2006). Once at or near the seabed, larvae (whether from spawning or brooding species) sense the substratum and actively search for a suitable attachment site (reviewed in Gleason \& Hofmann 2011, Jones et al. 2015) using a range of sensory capabilities (our Fig. 4; Young 1995). These sensory capabilities comprise the detection and discrimination of light fre- 

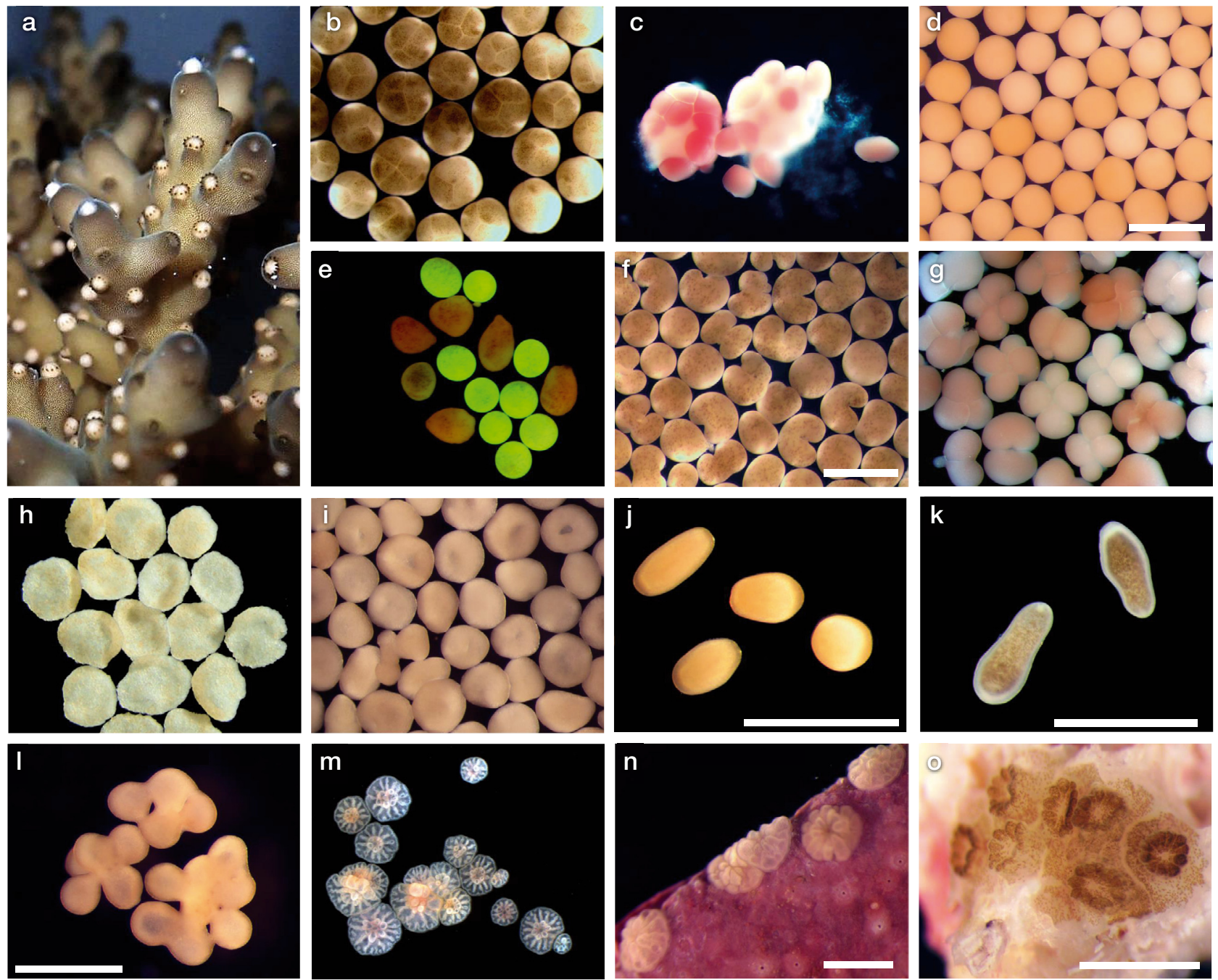

Fig. 3. Coral developmental stages. (a) Egg-sperm bundles setting inside mouths of polyps in Acropora loripes. (b) Intact, packed egg-sperm bundles of Montipora digitata immediately after release. (c) Acropora longicyathus egg-sperm bundles dissociating, releasing individual eggs and sperm from the bundle centres. (d) Unfertilised eggs of A. spathulata after 30 min of rounding out. (e) Unfertilised eggs of $M$. digitata under fluorescence microscopy showing variable green-fluorescent protein signals. (f) Early cleavage of fertilised M. digitata eggs. Note the presence of endosymbiotic dinoflagellates in these vertical transmitters. (g) A. tenuis $3 \mathrm{~h}$ after fertilisation in early cleavage. (h) Delicate 'prawn-chip' stage of Montipora capitata $15 \mathrm{~h}$ after fertilisation. Note the presence of endosymbiotic dinoflagellates. (i) A. loripes $16 \mathrm{~h}$ after fertilisation, rounding out into the gastrula stage. (j) Platygyra daedalea larvae beginning to elongate. (k) Fully developed and competent larvae of $M$. digitata with dense endosymbionts. Note the fully differentiated epidermis that lacks symbionts. (l) Mycedium elephantotus chimeras formed from the fusion of 4-8 individual embryos. $(\mathrm{m}) \mathrm{A}$. millepora recruits of various size classes resulting from fragmentation of blastomeres of 2-, 4-, or 8-cell embryos during early cleavage. (n) A. spathulata spat (single polyps) 2 d post-settlement. Note the absence of endosymbionts. (o) Montipora digitata coral spat settled in an aggregation, $2 \mathrm{~d}$ post-settlement. Note the presence of endosymbionts. Scale bars $=1 \mathrm{~mm}$. Photos in (a), (g), and (m): Andrew Negri; (c): Andrew Heyward; (b), (d-f), $(\mathrm{h}-\mathrm{l})$, and $(\mathrm{n}, \mathrm{o})$ : Carly Randall

quencies (Lewis 1974, Babcock \& Mundy 1996, Mundy \& Babcock 1998, Strader et al. 2015), gravity, hydrostatic pressure (Stake \& Sammarco 2003), possibly sound (Vermeij et al. 2010), and biochemical signals (Morse et al. 1996, Negri et al. 2001, Gleason et al. 2009, Tebben et al. 2015) (our Fig. 4). While the larvae of many coral species require a chemical cue of biological origin (inducer or morphogen) to induce settlement, this may not be a stringent requirement for all corals, as larvae of some species appear to settle spontaneously (Loya 1976, Harrison \& Wallace 1990, Baird \& Morse 2004). A broad range of cues (Section 5.2) can initiate settlement. Receptors on the ovoid larva detect the cues, and this triggers a cas- 


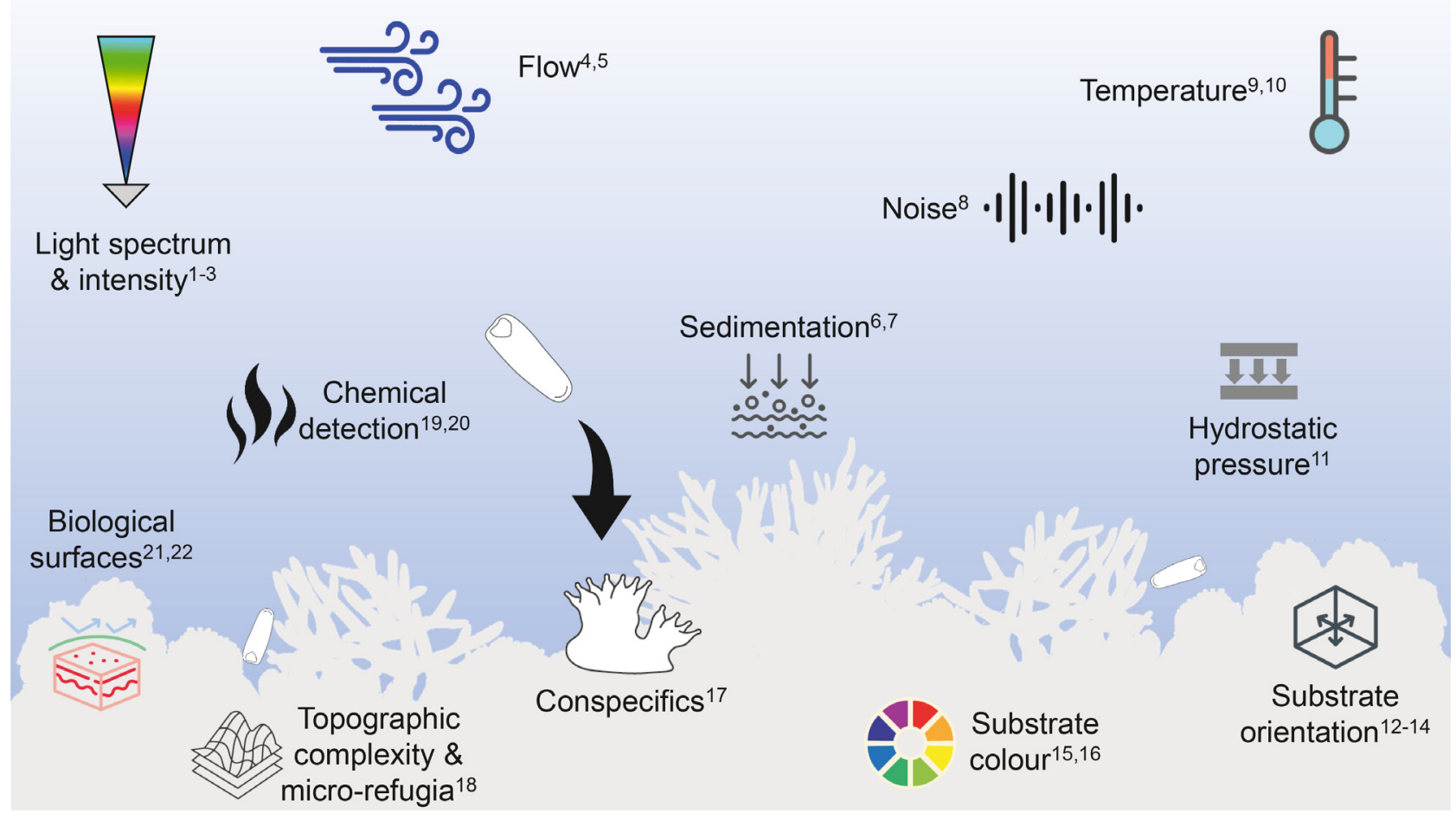

Fig. 4. Schematic diagram of the general physical, chemical, and biological factors (cues) that guide larvae to settlement locations and influence and trigger larval settlement on the reef, with example references for each factor. ${ }^{1}$ Babcock \& Mundy (1996), ${ }^{2}$ Mundy \& Babcock (1998), ${ }^{3}$ Strader et al. (2015), ${ }^{4}$ Roberts (1997), ${ }^{5}$ Hata et al. (2017), ${ }^{6}$ Babcock \& Davies (1991), ${ }^{7}$ Jones et al. (2015), ${ }^{8}$ Vermeij et al. (2010), ${ }^{9}$ Edmunds et al. (2001), ${ }^{10}$ Randall \& Szmant (2009a), ${ }^{11}$ Stake \& Sammarco (2003), ${ }^{12}$ Goreau et al. (1981), ${ }^{13}$ Doyle (1975), ${ }^{14}$ Fadlallah (1983), ${ }^{15}$ Mason et al. (2011), ${ }^{16}$ Foster \& Gilmour (2016), ${ }^{17}$ Da-Anoy et al. (2017),

${ }^{18}$ Whalan et al. (2015), ${ }^{19}$ Tebben et al. (2015), ${ }^{20}$ Gleason et al. (2009), ${ }^{21}$ Morse et al. (1996), ${ }^{22}$ Negri et al. (2001)

cade of internal biochemical and molecular signals (Grasso et al. 2011) that result in attachment of the aboral end, and initiation of metamorphosis into a sessile polyp (our Fig. 3m-o; Harrison \& Wallace 1990).

The time to settlement competency in larvae of broadcast spawners is species-specific and may follow a normal distribution within a cohort. Typically, first settlement is observed around $3 \mathrm{~d}$ after spawning at water temperatures of $26-28^{\circ} \mathrm{C}$ (Connolly \& Baird 2010, Figueiredo et al. 2013, Jones et al. 2015), with a majority competent within 4-6 d. By contrast, brooded larvae often may settle within a few hours after release from parent polyps, although some planulae remain competent for months (Stephenson 1931, Harrigan 1972, Shlesinger \& Loya 1985, Richmond 1987, Harrison \& Wallace 1990).

Metamorphosis of most species occurs within $24 \mathrm{~h}$ of substrate attachment (but see Nozawa \& Harrison 2000), when the larva has morphed into a disc-shaped structure with 6 incipient mesenteries radiating outward from a central mouth (Figs. $1 \& 3 \mathrm{~m}-\mathrm{o}$ ). Tentacles usually become apparent within $48 \mathrm{~h}$ (our Fig. 3o;
Harrison \& Wallace 1990, Heyward \& Negri 1999). While metamorphosis usually closely follows attachment, the cues for attachment and metamorphosis can be distinct and temporally uncoupled, with attachment occurring days to weeks before metamorphosis (e.g. Platygyra daedalea, Nozawa \& Harrison 2000; some Acropora species, Harrison 2006).

The hierarchy of cues, from subtle physical signals to strong and specific chemical inducers, also differs among species, enabling larvae to identify speciesspecific settlement sites that may optimise postsettlement survival and fitness (Morse et al. 1988, Raimondi \& Morse 2000, Baird et al. 2003, Baird \& Morse 2004, Golbuu \& Richmond 2007, Gleason \& Hofmann 2011). Settlement on light-exposed upper surfaces, for example, may favour energy acquisition via photosynthesis by symbionts; however, in this orientation, the $\sim 1 \mathrm{~mm}$ juvenile polyps may be more prone to predation, overgrowth by algae, and smothering by sediments (Vermeij 2006, Gleason \& Hofmann 2011, Jones et al. 2015). Attachment of larvae to dark undersurfaces may reduce these hazards, but could cause reduced growth from light limitation or competition 
from encrusting taxa. A successful strategy for the acroporids is to settle near underside edges somewhat protected from predation, grazing, and physical dislodgement, yet receiving enough light to promote colony growth (Mizrahi et al. 2014, dela Cruz \& Harrison 2017). Larvae of many species also favour settling in microrefugia such as in corners, crevices, or hollows of similar size to their diameter (Petersen et al. 2005, Nozawa 2008, Okamoto et al. 2008, Doropoulos et al. 2012b, 2016, Whalan et al. 2015). Older juveniles, however, tend to be found on exposed surfaces, reflecting the strong influence of post-settlement mortality on determining adult coral distributions (Babcock \& Mundy 1996, Mizrahi et al. 2014, Doropoulos et al. 2016, dela Cruz \& Harrison 2017).

\subsection{Settlement cues and inhibitors}

Larval settlement can be triggered by a broad range of abiotic cues, including surface topography (Whalan et al. 2015) and colour (Mason et al. 2011, Foster \& Gilmour 2016); however, biochemical inducers produced by crustose coralline algae (CCA) (our Fig. 3n; Morse et al. 1996, Harrington et al. 2004, Tebben et al. 2015) and microbial biofilms (Harrigan 1972, Webster et al. 2004, Tran \& Hadfeld 2011, Sharp et al. 2015) are considered more influential in triggering settlement in many species (Gleason \& Hofmann 2011, Jones et al. 2015). Choice experiments have demonstrated clear coral-algal specificity for some species (Morse et al. 1996, Harrington et al. 2004, Ritson-Williams et al. 2010, 2016, Davies et al. 2014); e.g. Acropora spp. larvae settle at higher rates on cryptic Titanoderma prototypum (Harrington et al. 2004). Less-preferred CCA species may overgrow the juvenile coral or shed surface layers, resulting in the dislodgement of the coral (Harrington et al. 2004).

The specific components of CCA and biofilms that induce settlement remain elusive. Reported chemical inducers associated with CCA include a sulphated glycosaminoglycan (Morse \& Morse 1991), a macrodiolide (Kitamura et al. 2009), glycoglycerolipids and polysaccharides (Tebben et al. 2015), and mixtures of a bromotyrosine derivative and carotenoids (Kitamura et al. 2007). Tetrabromopyrrole (TBP) isolated from the biofilm bacterium Pseudoalteromonas sp. induces rapid metamorphosis in some species, but is not always preceded by attachment and is relatively unstable (Tebben et al. 2011, Sneed et al. 2014). Similarly, the neuroactive signalling peptide GLW-amide induces metamorphosis in acroporid corals and can be readily synthesised, but permanent attachment of larvae is not always achieved (Iwao et al. 2002, Erwin \& Szmant 2010, Tebben et al. 2015).

A range of toxicants, including metals, pesticides, petroleum products, and other industrial products, have been shown to impact larval settlement (Negri \& Heyward 2000, Reichelt-Brushett \& Harrison 2000, Negri et al. 2005, Lam et al. 2015, Hudspith et al. 2017), and the physical blocking of cues can impede settlement as well. A very thin layer of sediment, for example, can prevent settlement on substrates with strong cues, and when removed, a legacy impact on the inductive capacity of the substrate may remain (Ricardo et al. 2017). Elevated temperature and $p \mathrm{CO}_{2}$ exposure can also directly reduce settlement rates and increase post-settlement mortality (Randall \& Szmant 2009a,b, Albright et al. 2010, Heyward \& Negri 2010, Albright \& Langdon 2011, Doropoulos et al. 2012a, but see Putnam et al. 2008), but can also negatively impact the biota that induce coral settlement, causing the broad-scale impairment of natural recruitment (Kuffner et al. 2008, Doropoulos et al. 2012a, Webster et al. 2013, Fabricius et al. 2015, 2017).

\subsection{Optimising coral settlement for restoration}

Understanding the cues, and particularly the biochemical inducers, that control larval settlement can facilitate the attachment of mass-cultured larvae onto natural or artificial substrata for restoration.

Successful settlement on any surface typically follows 'biological conditioning' for several weeks, for the development of microbial biofilms and recruitment of CCA (Harrigan 1972, Harrison \& Wallace 1990, Webster et al. 2004), or artificial induction (Guest et al. 2014, Omori \& Iwao 2014, Chamberland et al. 2017). Small ( $\sim \mathrm{mm}$ ) chips of live or dead CCA have reliably been used to attract and trigger larval settlement onto surfaces in experimental studies (Morse et al. 1996, Heyward \& Negri 1999) and this method could be applied to settle cultured larvae onto most natural and artificial surfaces for deployment in restoration. However, scaling-up this process requires the harvesting or culturing of CCA, and the species used may not actively induce settlement of all target species (Baird \& Morse 2004, Davies et al. 2014).

Applying natural biochemical inducers from CCA and biofilms onto surfaces for reef rehabilitation has been considered for over 2 decades (D. E. Morse et al. 1994, A. Morse et al. 1996). This approach is dependent on extracting the active chemicals pro- 
duced by the CCA or biofilm and immobilising the chemicals on a surface (D. E. Morse et al. 1994, A. Morse et al. 1996). The application of these chemicals to artificial surfaces for reef restoration would require mass isolation or synthesis of complex biochemicals, which can be unstable and costly, and none have so far proven to have universal activity across species. The application of natural and artificial inducers to settle larvae en masse requires more fundamental research, and currently, field or laboratory conditioning of surfaces to develop multi-species CCA and bacterial biofilms represents a less controlled but more feasible approach to settle a diversity of larvae for restoration.

Site selection by competent larvae is an important consideration for larval reseeding. Changes in settlement behaviour commence in the water column before a physical encounter between a larva and the substrate occurs, where waterborne chemicals associated with benthic organisms or pollutants may attract or repel them. Because allelopathic effects can extend well beyond the substrate boundary layer (Birrell et al. 2005, 2008, Morrow et al. 2016), they may drive larval selection or rejection of a settlement site. The degree to which larvae are capable of actively selecting among settlement sites through vertical positioning, however, is a matter of debate (Baird et al. 2014, Dixson et al. 2014, Hata et al. 2017), and may be limited to a small spatial scale, and to the crawling phase after the larvae have contacted the substrate.

Given the highly sensitive nature of larvae to physical, biological, and chemical agents, it is critical to evaluate and mitigate potential settlement inhibitors, particularly at a site where recruitment of larvae is a core restoration strategy (Beyer et al. 2018). The risks posed by settlement inhibitors at candidate restoration sites can be quantified by comparing in situ water quality measurements with thresholds derived from laboratory assays. In addition, there is mounting evidence that stressors and inhibitors can interact cumulatively to reduce coral settlement (Humanes et al. 2017) and thus should be considered in the selection and management of sites for restoration.

\subsection{Artificial substrates for use in reef restoration}

The artificial substrate most suitable for reef restoration depends on the goal and scale of the project (Spieler et al. 2001, Chamberland et al. 2015, 2017, Barton et al. 2015), and practitioners should consider the effectiveness, cost, environmental impact and the feasibility of use in large-scale applications. Almost any solid material can be used to settle coral larvae; however, materials differ in their composition and succession of colonising communities, resulting in differences in their abilities to attract and induce metamorphosis, and to reduce competition with other benthic organisms. For example, ceramic tiles are widely used for assessing settlement in situ, in part because they provide colonising CCA with a competitive advantage over other encrusting and fouling organisms (Harriott \& Fisk 1987). As settlement cues are often species-specific, the settlement surface and subsequent successional biofouling community likely bias the settling-coral community.

The shape and topography of artificial substrates can be designed and manufactured to produce an optimal settlement habitat. Larvae are drawn to small crevices and areas free of sediments and grazers (our Section 5.1; Babcock \& Davies 1991, Doropoulos et al. 2016, Ricardo et al. 2017). Several organisations are developing 'seeding units' designed to maximise recruitment success by incorporating natural microrefugia (e.g. Chamberland et al. 2017). Past restoration projects have improved recruit survival by using grates, meshes, or poles that provide a range of angles for settlement, while also allowing sediments to pass through (Omori et al. 2006, Suzuki et al. 2011, Higa \& Omori 2014, Ng et al. 2016). Three-dimensional printing technology is increasingly applied to help replicate the complex shapes of naturally occurring reefs (Mohammed 2016). Not all materials are easily shaped, however, and malleability and ease of manufacture of complex surfaces to improve restoration success need to be carefully considered.

Ease of deployment and suitability for the receiving environment are also important considerations. Substrates that need to be manually and individually attached to the seafloor (e.g. small recruitment substrates) are likely to be the most expensive and least practical to up-scale. By contrast, substrates that can be deployed from the surface with less effort, such as tetrapods designed to maximise the chance of wedging into the reef structure and increase retention (Chamberland et al. 2017), could be more economical at scale, noting that ideal substrates may vary by environment. Finally, it is imperative to consider the potential long-term environmental and ecological impacts of the selected material before introduction into the environment, where it may act as, or generate, pollution or marine debris. Some plastics have been associated with coral diseases (Lamb et al. 2018), and microplastics generated from the breakdown of plastics in the marine environment impact 
many organisms, including corals (Hall et al. 2015, Reichert et al. 2018).

\section{RECRUITMENT AND POST-SETTLEMENT SURVIVAL}

Early post-settlement survival is a primary bottleneck and challenge for coral restoration. Coral spat are particularly susceptible to predation, competition, and stochastic disturbances, and need to grow quickly to escape this vulnerable phase. Most newly settled corals are also aposymbiotic and must establish symbioses with a suite of partners to survive. Reducing predation and competition for young restored corals, both directly and indirectly, and providing recruits with targeted symbiotic partners, represent opportunities to overcome this bottleneck.

\subsection{Density-dependent processes in recruitment and post-settlement survival}

Settlement success can increase with larval density (Heyward et al. 2002, Suzuki et al. 2012, Doropoulos et al. 2018), but dense cultures may be suboptimal for larval health (Guest et al. 2010, Pollock et al. 2017) or carry downstream risks. Higher larval densities can increase gregarious settlement (our Fig. 3m, o) up to a density-dependent parabolic threshold (Suzuki et al. 2012, Doropoulos et al. 2017, 2018), which can accelerate growth and improve survival to a point (Suzuki et al. 2012). The availability of substrate with appropriate settlement cues can also interact with density-dependent biological processes; clustered patterns in the benthic community can encourage the clustering of spat around a settlement cue. On degraded reefs, a reduction in quality substrate may further encourage clustered settlement around rare cues and promote density-dependent recruitment bottlenecks (Vermeij \& Sandin 2008, Albright et al. 2010, dela Cruz \& Harrison 2017, Fabricius et al. 2017).

Mortality in the first year after settlement can be extremely high (>30-99\%) (Loya 1976, Babcock 1985, Babcock \& Mundy 1996, Wilson \& Harrison 2005, Davies et al. 2013, Suzuki et al. 2018). Stochastic processes like accidental grazing and storms contribute significantly to juvenile mortality (Mumby 1999, Davies et al. 2013, Trapon et al. 2013), and the drivers of mortality shift with life stage and size. For example, small juveniles 1-2 mo old are more susceptible to accidental grazing (Trapon et al. 2013) compared with larger 10-14 mo old juveniles (Davies et al. 2013). Generally, mortality pressures continue to act on coral juveniles until they reach a sizeescape threshold, or size refuge, when mortality significantly declines (Babcock \& Mundy 1996, Doropoulos et al. 2012b, dela Cruz \& Harrison 2017). This size refuge may differ across species but can be around $5 \mathrm{~mm}$ in diameter or 3-9 mo old (Babcock \& Mundy 1996, Doropoulos et al. 2012b). Furthermore, juvenile mortality after settlement can vary in a density-dependent manner. Dense settlement, for example, may lead to higher predation through predator attraction (Gallagher \& Doropoulos 2017), or alternatively could lead to decreased predation by reaching size-escape thresholds more quickly (Raymundo \& Maypa 2004, Doropoulos et al. 2012b).

\subsection{Maximising post-settlement survival in reef restoration}

A variety of methods have been proposed to either reduce predation on, or competition with, spat to overcome post-settlement survival bottlenecks for coral restoration. Firstly, substrates have been engineered with multiple surface orientations and microtopography, such as corners, crevices, holes, and divots, to offer a refuge from accidental grazing and to limit sedimentation impacts (Nozawa 2008, Chamberland et al. 2017). Materials with embedded antifouling compounds that target and prevent direct competition from other benthic organisms are being explored (Tebben et al. 2014), as are materials that have unpalatable embedded compounds that aim to reduce grazing pressure and deter corallivores.

Secondly, co-culturing techniques have been trialled, whereby coral recruits or fragments are reared alongside grazers, in a multi-trophic aquaculture system, and then deployed together. For example, co-culturing of coral spat with herbivorous gastropods such as Trochus spp. and Clypeomorus spp. snails (Omori 2005, Villanueva et al. 2013, Omori \& Iwao 2014, Toh et al. 2016) and echinoderms (Toh et al. 2016, Craggs et al. 2019) has been found to increase spat survival. Thus, herbivorous gastropods, echinoderms, and fishes, which already are routinely used to control algae in large-scale coral nurseries, offer opportunities for enhanced production efficiency. Furthermore, Spadaro (2014) reported preliminary success in deploying large herbivorous brachyuran crabs with high site fidelity at coral restoration locations in the Caribbean, indicating that in situ co-culturing also may be beneficial at restoration sites. 


\subsection{Size matters: improving restoration outcomes with chimeras}

Coral larvae tend to settle gregariously (our Fig. $3 \mathrm{~m}, \mathrm{n}$ ) and occasionally form natural chimeras (Amar et al. 2008, dela Cruz \& Harrison 2017), which can rapidly increase the size of the juvenile by an order of magnitude, and accelerate growth to the sizeescape threshold (Raymundo \& Maypa 2004, Doropoulos et al. 2012b, 2018, Suzuki et al. 2012). Chimeras develop from the fusion of genetically distinct coral embryos (our Fig. 31; Jiang et al. 2015), juveniles (our Fig. 3m,n; e.g. Raymundo \& Maypa 2004, Amar et al. 2008) or adults (Puill-Stephan et al. 2009), and may confer several ecological advantages such as faster growth, earlier sexual maturation, and increased competitive ability (Rinkevich \& Weissman 1987, 1992, Puill-Stephan et al. 2009, Rinkevich et al. 2016). The fusion of Pocillopora damicornis larvae resulted in higher growth and survival of juveniles (Raymundo \& Maypa 2004), and chimeras produced from brooded Stylophora pistillata larvae exhibited increased survival compared with individual juveniles (Amar et al. 2008). Yet, the ability of corals to discriminate self from non-self (allorecognition) and to tolerate chimeric colonies varies among species. Allorecognition in corals is driven by mechanisms of genetic histocompatibility (Heyward \& Collins 1985, Heyward \& Stoddart 1985, Stoddart et al. 1985), which develop as juveniles mature (Hidaka 1985, Hidaka et al. 1997). Chimerical full-sibling juveniles tend to exhibit the highest rates of stable post-settlement survival compared with half and non-sibling juveniles (Nozawa \& Loya 2005, Puill-Stephan et al. $2012 b$ ), and chimera formation at the larval or early recruit stage, before the maturation of immune recognition mechanisms, can increase fusion success (Hidaka 1985, Hidaka et al. 1997, Wilson \& Grosberg 2004, Puill-Stephan et al. 2012a,b, Schweinsberg et al. 2015). Thus, forming chimeras from related individuals early in ontogeny, during the embryo and larval stages, is likely to have the best outcome. Whether coral chimera formation can be controlled to yield a net increase in surviving recruits remains an area of current research (Cooper et al. 2014, Barton et al. 2015, Forsman et al. 2015).

\section{CORAL SYMBIOSES}

Central to a healthy coral are relationships with associated microorganisms, which have profound implications for coral health, stress tolerance, and acclimation response (Mieog et al. 2009). Mutually beneficial symbioses with photosynthetic dinoflagellates (Symbiodiniaceae, sensu LaJeunesse et al. 2018) and enduring partnerships with an array of bacterial, archaeal, fungal, protistan, and viral associates together form the coral holobiont (Bourne et al. 2016). Understanding when and how coral symbioses are established, and the capacity for these relationships to be manipulated and maintained is an active area of research in coral restoration.

\subsection{Establishment, maintenance, and specificity of symbiotic partnerships}

The most well studied coral symbionts are dinoflagellates of the family Symbiodiniaceae with densities $>10^{6}$ cells $\mathrm{cm}^{-2}$ providing up to $90 \%$ of the coral's nutritional requirements through translocation of photosynthates and other essential nutrients (Muscatine \& Porter 1977). The amount of carbon and nitrogen translocated to the coral host, however, can vary substantially among species and Symbiodiniaceae clades (Yellowlees et al. 2008, Davy et al. 2012, Tremblay et al. 2014) and under different environmental conditions (Little et al. 2004, Reynolds et al. 2008, Cantin et al. 2009, Hume et al. 2015). Bacterial and archaeal symbionts also occur at densities as high as $10^{6}$ cells $\mathrm{cm}^{-2}$ (Garren \& Azam 2012), with the diversity of these prokaryotic communities often exceeding thousands of distinct taxa (Sunagawa et al. 2010, Blackall et al. 2015). While these microbes cycle essential nutrients (carbon, nitrogen, sulphur, and phosphate) and provide trace metals, vitamins, and other cofactors (Bourne et al. 2016), examples of specific prokaryotic symbionts being unequivocally assigned functional roles are rare.

Early molecular studies indicated that some coral species form exclusive partnerships with a single Symbiodiniaceae type, whereas other species are known to associate with multiple types that vary in their relative abundance over time and space (Little et al. 2004, Abrego et al. 2009a,b, Fabina et al. 2012, Byler et al. 2013, Boulotte et al. 2016, Poland \& Coffroth 2017). These symbionts can be shared via parental gametes (i.e. vertical transmission), assimilated solely from the surrounding environment (i.e. horizontal transmission), or acquired through a mixture of both strategies (Byler et al. 2013, Quigley et al. 2018a). Vertical transmission of a locally adapted Symbiodiniaceae community may 
benefit species with localised dispersal (Underwood et al. 2007, Sherman 2008, Noreen et al. 2009, Warner et al. 2016), but could also be disadvantageous if environmental conditions change or if larvae are dispersed to novel environments. Alternatively, a horizontally acquired community may offer more flexibility under variable environmental conditions (Abrego et al. 2012, Boulotte et al. 2016, Quigley et al. 2017a, 2018a). Genetic analyses of relatedness and preferential selection experiments, however, have demonstrated that for both transmission modes, Symbiodiniaceae communities are, at least in part, regulated by their host and are not random (Yamashita et al. 2014, Quigley et al. 2017a, 2018a).

For most coral species, the exact point at which a Symbiodiniaceae symbiosis is initiated, and the environmental origins of horizontally transmitted symbionts, remain unclear. Symbiodiniaceae, which can also be free-living, have been recovered from seawater and substrates of coral reefs, but their diversity and availability for host uptake is not well known (Adams et al. 2009, Cumbo et al. 2013, Quigley et al. 2017 b). Larvae and juveniles of some Acropora species can establish symbiosis with Symbiodiniaceae shortly after exposure to local sediments (Adams et al. 2009, Cumbo et al. 2013). Yet, the diversity of Symbiodiniaceae residing within sediments is much greater than the diversity in corals, indicating that juvenile corals selectively uptake Symbiodiniaceae and/or certain types and sizes have higher infectivity (Yamashita et al. 2013, 2014, 2018, Biquand et al. 2017, Quigley et al. 2017b).

How the Symbiodiniaceae community changes during juvenile development is also poorly understood. For example, the brooding coral Porites astreoides showed substantial variation in the Symbiodiniaceae community throughout ontogeny and under different environmental conditions (Reich et al. 2017). Yet, parental effects (e.g. the influence of the maternal environment during gamete development) also explain a significant amount of the variation in symbiont composition in the spawning species Acropora tenuis (Quigley et al. 2016). Thus, it remains largely unknown how flexible or deterministic the host-symbiont community is for the vast majority of coral species.

The mode of transmission of prokaryotic symbionts, including bacterial, archaeal, fungal, protistan, and viral associates, constitutes a critical research priority. There is some indication that brooding species transmit at least some of these symbionts vertically, whereas species that rely on external fertilisa- tion acquire many of these symbionts horizontally (Apprill et al. 2009, Sharp et al. 2012). However, spawning corals can vertically transmit some components of the microbiome via mucus contact during spawning (Leite et al. 2017), and coral-associated bacteria can exhibit chemotaxis towards chemicals released from the coral, which likely influences the establishment and maintenance of species-specific host-microbe interactions (Tout et al. 2015).

\subsection{Environmental control over symbiotic partnerships}

Symbiotic partnerships between corals and microorganisms are sensitive to environmental perturbations, and symbiotic dysbiosis (i.e. imbalance) can represent a significant challenge to coral survival. The ability of some species to establish flexible partnerships with tolerant symbionts (Symbiodiniaceae or bacteria), however, could confer a plasticity that underpins transgenerational acclimatisation (Webster \& Reusch 2017). For instance, juvenile Acropora species can increase the relative abundance of tolerant Symbiodiniaceae under higher seawater temperatures (Abrego et al. 2012, Yorifuji et al. 2017), while some adult corals can acquire increased thermal tolerance by changing their dominant Symbiodiniaceae type (Berkelmans \& van Oppen 2006). At higher seawater temperatures, the larvae of some species can establish symbiosis with novel and thermally tolerant symbionts, while reducing their association with heat-sensitive Symbiodiniaceae (Cumbo et al. 2018). Furthermore, corals containing thermally tolerant algal symbionts are much more abundant on reefs that have been severely affected by recent climate change (Baker 2003, Baker et al. 2004), and Symbiodiniaceae associations can vary by host depth and light conditions (Iglesias-Prieto et al. 2004, Bongaerts et al. 2013, Nitschke et al. 2018).

The environmental sensitivity of coral-associated bacterial communities is also well established, with a shift towards opportunistic microorganisms and potential pathogens under ocean warming and ocean acidification (reviewed in Bourne et al. 2016). This sensitivity has been primarily documented with adult corals, with little understanding of microbial responses in early life-history stages. Furthermore, while the loss of symbionts has been correlated with declining host health, there are few examples of favourable symbiotic bacterial shifts that enhance growth or confer a competitive advantage under environmental change. 


\subsection{Controlling symbiont communities in restored corals}

Although there is some support for symbiont switching in adult corals (Boulotte et al. 2016, Quigley et al. 2019), early juveniles may be the opportune age to initiate infection with both environmentally tolerant Symbiodiniaceae communities, and beneficial-bacterial partners. This opportunity window precedes the development of an immune response during the juvenile stage and varies across coral taxa, but may take a few months to years (Little et al. 2004, Abrego et al. 2009b, Puill-Stephan et al. 2012a). Administering a 'probiotic' treatment, which incorporates a community of beneficial symbionts, could allow researchers to control the early 'infection' of coral settlers with select communities, thereby increasing resilience and optimising growth and fitness. As a first step, Damjanovic et al. (2017) demonstrated that a single microbial inoculation of adult corals drove a shift in the microbiome. Similarly, Rosado et al. (2018) showed that a consortium of native and putatively beneficial microorganisms administered as a probiotic to adult corals was able to partially mitigate coral bleaching in a laboratory thermal-stress experiment. Defining the ontogenetic variability in the microbiome and the speciesspecific life-history window when corals have considerable flexibility to associate with a diverse range of environmentally acquired and potentially stress-tolerant symbionts prior to community specialisation should be a future research priority.

\section{AGE AND SIZE AT SEXUAL MATURATION}

It can take 3 to 8 yr or more for a coral to reach sexual maturation (Kojis \& Quinn 1981, Babcock 1991, dela Cruz \& Harrison 2017). Reducing this duration to promote early maturation has many potential restoration applications. Yet, the factors that govern the onset of sexual maturation in corals, and how phenotypically plastic that onset may be, are largely unknown.

\subsection{Is sexual maturation determined by age or size?}

For most colonial organisms, including scleractinians, a critical-size threshold must be reached to trigger the onset of sexual maturation, beyond which, fecundity increases with size until a colony is fully reproductive (Connell 1973, Loya 1976, Kojis \& Quinn
1981, 1985, Harriott 1983, Szmant-Froelich 1985, Wallace 1985, Babcock 1991, Soong \& Lang 1992, Hall \& Hughes 1996). Only some corals in a population mature at the size threshold (Szmant-Froelich 1985, Babcock 1991, dela Cruz \& Harrison 2017), however, and estimates of that size have only been described for a handful of species, ranging widely from $2.3 \mathrm{~cm}^{2}$ in the brooder Favia fragum to $1600 \mathrm{~cm}^{2}$ in the spawner Acropora palmata (Soong \& Lang 1992). Soong (1993) identified a significant positive correlation between size at first reproduction and maximum colony size for 7 brooding and spawning Caribbean species, suggesting that larger species generally mature later and at a larger size than smaller ones (MacArthur \& Wilson 1967, Szmant-Froelich 1985), although this has yet to be investigated for most species. The onset of sexual maturation is difficult to predict, as it is likely to be influenced by spatio-temporal variation in biological condition (Harvell \& Grosberg 1988) and by variation in coral growth rates, which are in turn influenced by many factors, including competition (Rinkevich \& Loya 1985, Tanner 1995), light availability (Huston 1985, Lough \& Barnes 2000), nutrient profiles and concentrations (Tomascik \& Sander 1985, Fabricius 2005), symbiont communities (Jones \& Berkelmans 2010), and host genetics (Drury et al. 2017). Consequently, variations in these factors all have the potential to affect the timing of sexual maturation.

Fragmentation and partial-mortality events have the potential to reduce a colony's size below the critical threshold for reproduction. In these cases, the colony becomes small, while the polyps remain 'old', leading Connell (1973) to pose 2 questions: (1) Is sexual maturation in corals determined by polyp age or colony size?; and (2) Will a reduction in colony size result in a regression to a juvenile state? Kojis \& Quinn $(1981,1985)$ experimentally fragmented mature adult Goniastrea colonies into various size classes and found that sexual reproduction ceased when the total number of polyps was reduced below 30 , even after $2 \mathrm{yr}$ of recovery. However, when they compared reproductive colonies of the same size but different ages, they found that older colonies were more fecund, indicating that age also influences reproductive output. Similarly, Szmant-Froelich (1985) found that fragmenting adult Orbicella annularis colonies below $200 \mathrm{~cm}^{2}$ in surface area reduced or prevented gonad development. Subsequent fragmentation studies of spawning and brooding species found that both colony size and polyp age can influence fecundity (Ward 1995, Smith \& Hughes 1999, Zakai et al. 2000, Okubo et al. 2007, Kai \& Sakai 2008), and led Graham \& van Woesik (2013) to suggest that the reproductive 
response to fragmentation below the critical-size threshold may be binary and species-specific, where some species maintain gametogenesis while others regress to an immature state. Research over 30 yr has identified at least 7 considerations when predicting whether fragmented corals will reproduce: (1) size of the fragment; (2) age of the fragment; (3) shape of the fragment and location of polyps; (4) mode of polyp budding; (5) timing of fragmentation; (6) duration of fragment isolation; and (7) species (Table 1).

Table 1. Key factors to consider when fragmenting corals for restoration, to maintain the greatest possible reproductive output

\begin{tabular}{|c|c|c|c|}
\hline $\begin{array}{l}\text { Key } \\
\text { consideration }\end{array}$ & Description & Restoration optimisation & References \\
\hline $\begin{array}{l}\text { Size of the } \\
\text { fragment }\end{array}$ & $\begin{array}{l}\text { If a coral is fragmented below the mini- } \\
\text { mum-size threshold, the likelihood of } \\
\text { regression to a prepubescent state is high } \\
\text { and may result in resorption of oocytes }\end{array}$ & $\begin{array}{l}\text { Maintain fragments well above the } \\
\text { minimum-size threshold (mea- } \\
\text { sured by excluding infertile } \\
\text { margins). If not known, select } \\
\text { colonies }>25 \mathrm{~cm} \text { in diameter, as } \\
\text { most studies to date indicate } \\
\text { colonies of this size should be } \\
\text { sexually mature }\end{array}$ & $\begin{array}{l}\text { Kojis \& Quinn (1985), } \\
\text { Szmant-Froelich (1985), } \\
\text { Lirman (2000), } \\
\text { Zakai et al. (2000), } \\
\text { Okubo et al. (2007) }\end{array}$ \\
\hline $\begin{array}{l}\text { Age of the } \\
\text { colony }\end{array}$ & $\begin{array}{l}\text { There may be a minimum age at which a } \\
\text { colony can reach sexual maturation. } \\
\text { When colonies of the same size but } \\
\text { different ages are compared, the older } \\
\text { colony may be more fecund }\end{array}$ & $\begin{array}{l}\text { If known, select colonies well } \\
\text { above the minimum age of sexual } \\
\text { maturation to maximise spawning } \\
\text { output. If not known, select } \\
\text { colonies }>25 \mathrm{~cm} \text { in diameter, as } \\
\text { most studies to date indicate } \\
\text { colonies of this size should be } \\
\text { sexually mature }\end{array}$ & Kojis \& Quinn (1985) \\
\hline $\begin{array}{l}\text { Shape of the } \\
\text { fragment and } \\
\text { location of } \\
\text { polyps }\end{array}$ & $\begin{array}{l}\text { Colonies exhibit considerable spatial } \\
\text { variability in polyp fecundity. Colony } \\
\text { margins and axial polyps are often } \\
\text { infertile, and downward-facing tissue on } \\
\text { branches and vertical surfaces on mound- } \\
\text { ing corals have lower fecundity }\end{array}$ & $\begin{array}{l}\text { Optimise reproductive output by } \\
\text { collecting centrally located } \\
\text { fragments and fragments with } \\
\text { upper-facing surfaces. Limit the } \\
\text { creation of new colony margins }\end{array}$ & $\begin{array}{l}\text { Wallace (1985), } \\
\text { Soong \& Lang (1992), } \\
\text { Van Veghel \& Bak } \\
(1994), \\
\text { Nozawa \& Lin (2014) }\end{array}$ \\
\hline $\begin{array}{l}\text { Mode of polyp } \\
\text { budding }\end{array}$ & $\begin{array}{l}\text { Interior polyps newly produced by } \\
\text { intratentacular budding were fully fecund } \\
\text { in Favia fragum, whereas polyps newly } \\
\text { produced by extratentacular budding in } \\
\text { Pseudodiploria spp. were infertile }\end{array}$ & $\begin{array}{l}\text { Anticipate potentially higher } \\
\text { reproductive output from frag- } \\
\text { ments of species that bud intraten- } \\
\text { tacularly }\end{array}$ & Soong \& Lang (1992) \\
\hline $\begin{array}{l}\text { Timing of } \\
\text { fragmentation }\end{array}$ & $\begin{array}{l}\text { Timing within the gametogenic cycle can } \\
\text { influence fecundity post-fragmentation. } \\
\text { Fragmentation during early vitellogenesis } \\
\text { (i.e. yolk development) has been shown to } \\
\text { result in resorption of oocytes }\end{array}$ & $\begin{array}{l}\text { Fragment late in the gametogenic } \\
\text { cycle but limit fragmentation in the } \\
\text { days immediately prior to spawn- } \\
\text { ing to avoid stress-spawning }\end{array}$ & Okubo et al. (2007) \\
\hline $\begin{array}{l}\text { Duration of } \\
\text { fragment } \\
\text { isolation }\end{array}$ & $\begin{array}{l}\text { Some species may exhibit 'reproduction } \\
\text { adaptation', whereby polyps on fragments } \\
\text { that have been isolated for several years } \\
\text { (e.g. on individual branches) may become } \\
\text { fecund even if the fragment remains } \\
\text { below the critical-size threshold }\end{array}$ & $\begin{array}{l}\text { If collecting fragments near the } \\
\text { minimum-size threshold, select } \\
\text { those that appear to have been } \\
\text { isolated for a long duration, with } \\
\text { healed and growing margins }\end{array}$ & Szmant-Froelich (1985) \\
\hline Species & $\begin{array}{l}\text { Some species regress to an immature } \\
\text { state when fragmented below the mini- } \\
\text { mum-size threshold (i.e. Favia chinensis) } \\
\text { and others remain reproductively active } \\
\text { (e.g. Goniastrea aspera and Pseudodiplo- } \\
\text { ria strigosa) }\end{array}$ & $\begin{array}{l}\text { If known, select colonies that } \\
\text { remain reproductively active post- } \\
\text { fragmentation. When fragmenting } \\
\text { species that regress, create } \\
\text { fragments above the critical-size } \\
\text { threshold }\end{array}$ & $\begin{array}{l}\text { Kai \& Sakai (2008), } \\
\text { Graham \& van Woesik } \\
(2013)\end{array}$ \\
\hline
\end{tabular}




\subsection{Is it possible to artificially accelerate sexual maturation?}

Accelerating sexual maturation through the growth and isogenic fusion of microfragments (sensu Page et al. 2018) in a process called 're-skinning' (Forsman et al. 2015) has the potential to reduce generation times and consequently increase coral-recovery rates and restoration outputs. Preliminary results from fused microfragments of Orbicella faveolata (Forsman et al. 2015) indicate that sexual maturation may be artificially accelerated by promoting the fusion and growth of the colonies to the critical-size threshold (Page et al. 2018). More research is needed, however, to evaluate the suitability of this technique for other species and growth morphologies. For example, in some massive corals, the fecundity of individual polyps will be influenced not only by colony size (area) but also by tissue depth, which may be limited in re-skinned corals.

\section{FEASIBILITY OF LARGE-SCALE RESTORATION}

Restoring degraded reefs with sexually propagated corals is being considered or applied on reefs around the world at various spatial scales and with numerous approaches. Comprehensive desktop analyses comparing a multitude of approaches are currently underway to examine the benefits, risks, and feasibility of both influencing the long-term health and survival of corals, and facilitating acclimatisation and adaptation of coral populations at scale (The National Academies of Sciences, Engineering, and Medicine 2019; www.gbrrestoration.org). In Australia, a range of scalable methods are being considered that rely on the sexual propagation of corals, either through the capture and redirection of wild spawn, or from landand/or sea-based aquaculture production facilities. Preliminary analyses indicate that there are common bottlenecks to achieve cost and scale across all approaches, relating to key biological and ecological attributes of coral reproduction. For example, high in situ mortality post-settlement means (1) nurseryreared corals will need to be kept for weeks or months to pass a size-escape threshold, (2) the production numbers required to achieve scale will need to be very large, and (3) the estimated cost per deployed coral surviving to adulthood will be inflated (Omori 2019). The extent to which early growth and survival of corals can be enhanced will materially affect the cost and scale at which sexually produced corals can be feasibly used. Analyses thus far have also clarified that, while extensive effort needs to be applied to technological developments in coral sexual propagation, a significant amount of attention also needs to be directed toward investigating fundamental aspects of ecological benefits and risks, such as quantifying trade-offs in growth and thermal tolerance, and identifying the down-stream effects of spawning corals out of season. This research is required to adequately assess the feasibility of the proposed methods.

\section{CONCLUSIONS}

The success of coral restoration and adaptation interventions will vary among species, sites, reefs, and regions. Incorporating reef-building species that occupy a variety of ecological niches, encompass a range of reproductive modes, include a suite of morphological or functional forms, and include a diversity of species, will be required to facilitate and maximise recovery rates, with the end goal of restoring and maintaining ecosystem functions.

Based on current knowledge, we suggest that a combination of restoration approaches will deliver the greatest benefit, and that restoration interventions should (1) incorporate sexually reproduced corals across a variety of life-history stages, (2) consider the ecology of the target restoration site (Ladd et al. 2018) and implement deployment methods consistent with local ecological processes, (3) incorporate pre-adapted or stress-hardened coral stock, or incorporate methods that support natural processes of adaptation, (4) protect key ecological functions, (5) conserve sociocultural values, such as those held by Traditional Owners and a diverse range of stakeholders, and (6) be logistically feasible and at a cost point for deployment at large scale. Whether it is feasible to achieve these targets through scaled-up coral restoration remains an active area of investigation (Guest et al. 2014) that will require well-developed and integrated research and development plans (our Table 2).

Overcoming the research challenges outlined here will require an unprecedented level of collaboration across nations, research groups, and public and private sectors. To address fundamental research questions and achieve long-term success, researchers and practitioners working in reef restoration must also draw on expertise from vastly different scientific disciplines such as microbiology, genetics, restoration ecology, aquaculture, materials science, and engi- 
Table 2. High-priority knowledge gaps identified in the review and corresponding suggested approaches. Expected outcomes of the research for each section of the review are presented based on current state of knowledge

\begin{tabular}{|c|c|c|}
\hline $\begin{array}{l}\text { Areas of research that target } \\
\text { key knowledge gaps }\end{array}$ & Approaches to address knowledge gaps & Expected outcomes \\
\hline jametogenic & $\begin{array}{l}\text { - Large experimental systems with fine-scale control over ex situ } \\
\text { environmental conditions, with and without off-set seasonal and } \\
\text { diel cycles } \\
\text { - Histological sampling to identify the timing of gametogenesis in } \\
\text { the field } \\
\text { - Field monitoring of key functional groups (e.g. massive Porites) } \\
\text { to more accurately identify in situ spawning patterns } \\
\text { - Development of an integrated on-line system for collecting and } \\
\text { synthesizing regional or global spawning observations }\end{array}$ & $\begin{array}{l}\text { - Ability to predict more accurately which species will spawn, } \\
\text { where and when } \\
\text { - Aquaculture systems that enable manipulation of seasonal and } \\
\text { lunar cycles to synchronously spawn corals 'out-of-season' } \\
\text { - Ability to adjust diel timing of coral spawning to increase culture } \\
\text { efficiencies } \\
\text { - Better understanding of the molecular mechanisms and } \\
\text { environmental factors underpinning function of endogenous } \\
\text { reproductive rhythms in corals } \\
\text { - Knowledge to assess the risk of spawning asynchrony in } \\
\text { restored corals }\end{array}$ \\
\hline Characterizati & $\begin{array}{l}\text { - Field monitoring for the presence or absence of slick formation, } \\
\text { and coincident collection of environmental data } \\
\text { - Remotely sensed detection of spawn slicks } \\
\text { - Field sampling for histological and genetic identification of } \\
\text { species composition and diversity within slicks, and embryo } \\
\text { viability } \\
\text { - Field experimentation to contain, collect and transport spawn } \\
\text { slicks } \\
\text { - Field and lab experiments and modelling to understand and } \\
\text { quantify processes (including sperm density and gamete quality) } \\
\text { affecting coral fertilization success }\end{array}$ & $\begin{array}{l}\text { - Predictive models to estimate when and where spawn slicks will } \\
\text { form } \\
\text { - Ability to target slicks to maximize the diversity of species } \\
\text { harvested for restoration } \\
\text { - Ability to effectively harvest and transport spawn slicks for reef } \\
\text { restoration } \\
\text { - Knowledge of stocking densities that are adequate to ensure } \\
\text { self-sustaining fertilization and larval production }\end{array}$ \\
\hline $\begin{array}{l}\text { Identification of } \\
\text { and inhibitors }\end{array}$ & $\begin{array}{l}\text { - Laboratory-based biochemical and larval-behaviour assays to } \\
\text { identify inducers and inhibitors for a wider range of coral taxa, and } \\
\text { define relevant effective doses } \\
\text { Evaluation of the microhabitat and environmental factors, } \\
\text { including influence of biofilm succession, and conditioning timing } \\
\text { and duration on settlement and post-settlement survival in the lab } \\
\text { and field, for a wider range of species }\end{array}$ & $\begin{array}{l}\text { - Identification of cues to induce and improve settlement of a } \\
\text { diversity of coral taxa } \\
\text { - Set of 'best-practices' for settling a diversity of species (e.g. } \\
\text { culture conditions, densities, durations, flow rates, substrate } \\
\text { conditioning protocols) } \\
\text { - Ability to characterise and identify optimal candidate restoration } \\
\text { sites } \\
\text { - Ability to induce settlement at specifically targeted locations or } \\
\text { optimal 'receiving sites' }\end{array}$ \\
\hline Establishing sy & $\begin{array}{l}\text { - Laboratory and field experiments to build basic knowledge } \\
\text { around how (horizontally, vertically or dual mode transmission) } \\
\text { and when symbiosis gets established } \\
\text { - Genomic techniques to determine uptake and ontogenetic } \\
\text { variability in the microbiome from embryo to juvenile } \\
\text { - Laboratory inoculation experiments followed by out-planting } \\
\text { and time-series sampling to evaluate the feasibility of establishing } \\
\text { and maintaining select symbiotic partners } \\
\text { - Laboratory experiments to evaluate the impact of stress } \\
\text { hardening on embryos and larvae }\end{array}$ & $\begin{array}{l}\text { - Effective uptake and transmission methods to maximize sym- } \\
\text { biosis success and long-term maintenance } \\
\text { - Identification of symbiotic partners that may enhance coral } \\
\text { performance in a warming climate } \\
\text { - Stress-hardening methods to improve thermal tolerance of } \\
\text { embryos and larvae }\end{array}$ \\
\hline $\begin{array}{l}\text { Overcoming the } p \\
\text { survival bottlenec }\end{array}$ & $\begin{array}{l}\text { - Development of ecologically safe and effective juvenile } \\
\text { deployment substrates and efficient methods to deploy } \\
\text { - Laboratory choice and no-choice settlement experiments with a } \\
\text { suite of shapes and substrate types to identify optimal substrates } \\
\text { for post-settlement survival } \\
\text { - Field experiments to track post-deployment survival and } \\
\text { compare substrate performance across reefs, reef zones and } \\
\text { species and under different levels of competition and predation } \\
\text { - Field experiments to investigate density-dependent effects of } \\
\text { settlement on survival } \\
\text { - Laboratory experiements to test the effect of nutrition and } \\
\text { probiotic treatments on growth and survival, and evaluate a suite } \\
\text { of delivery methods }\end{array}$ & $\begin{array}{l}\text { - Species-specific ability to maximize post-deployment survival } \\
\text { and growth } \\
\text { - Ecologically effective and cost-efficient substrata for outplan- } \\
\text { ting corals } \\
\text { - Nutrition and probiotic profiles, concentrations, and delivery } \\
\text { methods that optimize growth and post-settlement survival }\end{array}$ \\
\hline $\begin{array}{l}\text { Identifying the factors that control } \\
\text { the onset of sexual maturity }\end{array}$ & $\begin{array}{l}\text { - Laboratory and field experiments with adult, fragmented, } \\
\text { microfragmented, and isogenically fused coral colonies to identify } \\
\text { the factors governing the onset of sexual maturation for a diversity } \\
\text { of species } \\
\text { - Laboratory experiments to determine the factors that promote } \\
\text { early maturation and identify what physiological/ecological } \\
\text { trade-offs are associated with early maturation (if any) }\end{array}$ & $\begin{array}{l}\text { - More accurate models of population growth and response to } \\
\text { restoration for a diversity of species } \\
\text { - Ability to shorten generation times by inducing early maturation } \\
\text { in selected strains of coral or young, isogenically fused corals }\end{array}$ \\
\hline Age and size at se & $\begin{array}{l}\text { - Temporal field sampling with histological analyses to identify } \\
\text { minimum size-thresholds for sexual maturation for a diversity of } \\
\text { species } \\
\text { - Laboratory experiments to determine the effects of fusion and } \\
\text { fission of colonies on reproductive output, including the effects of } \\
\text { timing, fragment size, age, etc. }\end{array}$ & $\begin{array}{l}\text { - Ability to optimise fragmentation and other asexual propagation } \\
\text { methods to maximise reproductive output }\end{array}$ \\
\hline $\begin{array}{l}\text { Coral aquaculture } \\
\text { and development }\end{array}$ & $\begin{array}{l}\text { - Development of automated high-throughput aquaculture } \\
\text { production } \\
\text { - Time series genomics sampling and analysis of batch cultures } \\
\text { throughout embryogenesis and larval development (culture } \\
\text { genetics) to identify the most successful genotypes and assess } \\
\text { the risk of 'lab-adapted' corals on potential performance on reefs }\end{array}$ & $\begin{array}{l}\text { - Ability to propagate corals in large quantities and at low cost } \\
\text { - Estimates of the risk of rearing 'laboratory-adapted' corals that } \\
\text { may result in maladapted genotypes that have impaired } \\
\text { performance on reefs }\end{array}$ \\
\hline
\end{tabular}


neering. Key knowledge gaps in the science of coral sexual reproduction are reported in Table 2 and offer a list of high-priority research questions to quickly move the field toward potentially feasible and costeffective restoration. We emphasise that no approach will be successful without swift and effective efforts to mitigate greenhouse gas emissions. Mitigation must go hand-in-hand with these restoration approaches, as intervention is intended only to temper decline and accelerate natural recovery at more local scales while global efforts take effect to slow the rate of ocean warming and acidification.

Acknowledgements. We thank B. Schaffelke for providing valuable comments on an earlier draft. This work was partially funded by the Australian Government through the Reef Restoration and Adaptation Program, a collaboration of leading experts formed to create a suite of innovative measures to help preserve and restore the Great Barrier Reef.

\section{LITERATURE CITED}

Abrego D, van Oppen MJH, Willis BL (2009a) Highly infectious symbiont dominates initial uptake in coral juveniles. Mol Ecol 18:3518-3531

Abrego D, van Oppen MJH, Willis BL (2009b) Onset of algal endosymbiont specificity varies among closely related species of Acropora corals during early ontogeny. Mol Ecol 18:3532-3543

Abrego D, Willis BL, van Oppen MJH (2012) Impact of light and temperature on the uptake of algal symbionts by coral juveniles. PLOS ONE 7:e50311

Adams LM, Cumbo V, Takabayashi M (2009) Exposure to sediment enhances primary acquisition of Symbiodinium by asymbiotic coral larvae. Mar Ecol Prog Ser 377: 149-156

* Albright R (2011) Reviewing the effects of ocean acidification on sexual reproduction and early life history stages of reef-building corals. J Mar Biol 2011:1-14

Albright R, Langdon C (2011) Ocean acidification impacts multiple early life history processes of the Caribbean coral Porites astreoides. Glob Change Biol 17:2478-2487

Albright R, Mason B (2013) Projected near-future levels of temperature and $p \mathrm{CO} 2$ reduce coral fertilization success. PLOS ONE 8:e56468

Albright R, Mason B, Miller M, Langdon C (2010) Ocean acidification compromises recruitment success of the threatened Caribbean coral Acropora palmata. Proc Natl Acad Sci USA 107:20400-20404

* Álvarez Noriega M, Baird AH, Dornelas M, Madin JS, Cumbo VR, Connolly SR (2016) Fecundity and the demographic strategies of coral morphologies. Ecology 97: 3485-3493

Amar KO, Chadwick NE, Rinkevich B (2008) Coral kin aggregations exhibit mixed allogeneic reactions and enhanced fitness during early ontogeny. BMC Evol Biol 8:126

Anthony K, Connolly SR, Willis BL (2002) Comparative analysis of energy allocation to tissue and skeletal growth in corals. Limnol Oceanogr 47:1417-1429
Anthony K, Bay LK, Costanza R, Firn J and others (2017) New interventions are needed to save coral reefs. Nat Ecol Evol 1:1420

Apprill A, Marlow HQ, Martindale MQ, Rappé MS (2009) The onset of microbial associations in the coral Pocillopora meandrina. ISME J 3:685-699

* Arai I, Kato M, Heyward A, Ikeda Y, Iizuka T, Maruyama T (1993) Lipid composition of positively buoyant eggs of reef building corals. Coral Reefs 12:71-75

Babcock RC (1984) Reproduction and distribution of two species of Goniastrea (Scleractinia) from the Great Barrier Reef Province. Coral Reefs 2:187-195

Babcock RC (1985) Growth and mortality in juvenile corals (Goniastrea, Platygyra and Acropora): the first year. In: Gabrie C, Salvat B (eds) Proc 5th Int Coral Reef Congress, Vol 4, Tahiti, p 355-360

*Babcock RC (1991) Comparative demography of three species of scleractinian corals using age and size dependent classifications. Ecol Monogr 61:225-244

* Babcock RC, Davies P (1991) Effects of sedimentation on settlement of Acropora millepora. Coral Reefs 9:205-208

* Babcock RC, Heyward AJ (1986) Larval development of certain gamete-spawning scleractinian corals. Coral Reefs 5:111-116

*Babcock R, Mundy C (1996) Coral recruitment: consequences of settlement choice for early growth and survivorship in two scleractinians. J Exp Mar Biol Ecol 206: 179-201

Babcock RC, Bull GD, Harrison PL, Heyward AJ, Oliver JK, Wallace CC, Willis BL (1986) Synchronous spawnings of 105 scleractinian coral species on the Great Barrier Reef. Mar Biol 90:379-394

* Babcock RC, Willis BL, Simpson CJ (1994) Mass spawning of corals on a high latitude coral reef. Coral Reefs 13: 161-169

* Baird AH, Morse ANC (2004) Induction of metamorphosis in larvae of the brooding corals Acropora palifera and Stylophora pistillata. Mar Freshw Res 55:469

*Baird AH, Babcock RC, Mundy CP (2003) Habitat selection by larvae influences the depth distribution of six common coral species. Mar Ecol Prog Ser 252:289-293

Baird AH, Guest JR, Willis BL (2009) Systematic and biogeographical patterns in the reproductive biology of scleractinian corals. Annu Rev Ecol Evol Syst 40:551-571

Baird AH, Emslie MJ, Lewis AR (2012) Extended periods of coral recruitment on the Great Barrier Reef. In: Yellowlees D, Hughes TP (eds) Proc 12th Int Coral Reef Symp, Cairns, p 1-5

Baird AH, Cumbo VR, Figueiredo J, Harii S, Hata T, Madin JS (2014) Comment on 'Chemically mediated behavior of recruiting corals and fishes: A tipping point that may limit reef recovery'. PeerJ Preprints 2:e628v1

* Baker AC (2003) Flexibility and specificity in coral-algal symbiosis: diversity, ecology, and biogeography of Symbiodinium. Annu Rev Ecol Evol Syst 34:661-689

Baker AC, Starger CJ, McClanahan TR, Glynn PW (2004) Corals' adaptive response to climate change. Nature 430: 741

Ball EE, Hayward DC, Reece-Hoyes JS, Hislop NR and others (2002) Coral development: from classical embryology to molecular control. Int J Dev Biol 46:671-678

* Barshis DJ, Ladner JT, Oliver TA, Seneca FO, TraylorKnowles N, Palumbi SR (2013) Genomic basis for coral resilience to climate change. Proc Natl Acad Sci USA 110:1387-1392 
Barton JA, Willis BL, Hutson KS (2015) Coral propagation: a review of techniques for ornamental trade and reef restoration. Rev Aquacult 9:238-256

Bassim K, Sammarco P (2003) Effects of temperature and ammonium on larval development and survivorship in a scleractinian coral (Diploria strigosa). Mar Biol 142: 241-252

Bassim K, Sammarco P, Snell T (2002) Effects of temperature on success of (self and non-self) fertilization and embryogenesis in Diploria strigosa (Cnidaria, Scleractinia). Mar Biol 140:479-488

Baums IB (2008) A restoration genetics guide for coral reef conservation. Mol Ecol 17:2796-2811

* Berkelmans R, van Oppen MJH (2006) The role of zooxanthellae in the thermal tolerance of corals: a 'nugget of hope' for coral reefs in an era of climate change. Proc R Soc B 273:2305-2312

Beyer HL, Kennedy EV, Beger M, Chen CA and others (2018) Risk-sensitive planning for conserving coral reefs under rapid climate change. Conserv Lett 11:e12587

Biquand E, Okubo N, Aihara Y, Rolland V and others (2017) Acceptable symbiont cell size differs among cnidarian species and may limit symbiont diversity. ISME J 11:1702

Birrell CL, McCook LJ, Willis BL (2005) Effects of algal turfs and sediment on coral settlement. Mar Pollut Bull 51: 408-414

Birrell CL, McCook LJ, Willis BL, Harrington L (2008) Chemical effects of macroalgae on larval settlement of the broadcast spawning coral Acropora millepora. Mar Ecol Prog Ser 362:129-137

Blackall LL, Wilson B, van Oppen MJH (2015) Coral—the world's most diverse symbiotic ecosystem. Mol Ecol 24: 5330-5347

Bongaerts P, Frade PR, Ogier JJ, Hay KB and others (2013) Sharing the slope: depth partitioning of agariciid corals and associated Symbiodinium across shallow and mesophotic habitats $(2-60 \mathrm{~m})$ on a Caribbean reef. BMC Evol Biol 13:205

Boulotte NM, Dalton SJ, Carroll AG, Harrison PL, Putnam HM, Peplow LM, van Oppen MJH (2016) Exploring the Symbiodinium rare biosphere provides evidence for symbiont switching in reef-building corals. ISME J 10: 2693-2701

Bourne DG, Morrow KM, Webster NS (2016) Insights into the coral microbiome: underpinning the health and resilience of reef ecosystems. Annu Rev Microbiol 70:317-340

Bouwmeester J, Baird AH, Chen CJ, Guest JR, Vicentuan KC, Berumen ML (2015) Multi-species spawning synchrony within scleractinian coral assemblages in the Red Sea. Coral Reefs 34:65-77

Bowden-Kerby A (2003) Coral transplantation and restocking to accelerate the recovery of coral reef habitats and fisheries resources within no-take marine protected areas: hands-on approaches to support communitybased coral reef management. In: 2nd Int Trop Mar Ecosyst Manage Symp, Manila, p 1-15

Brady AK, Hilton JD, Vize PD (2009) Coral spawn timing is a direct response to solar light cycles and is not an entrained circadian response. Coral Reefs 28:677-680

Bronstein O, Loya Y (2011) Daytime spawning of Porites rus on the coral reefs of Chumbe Island in Zanzibar, Western Indian Ocean (WIO). Coral Reefs 30:441

Burke LM, Reytar K, Spalding MD, Perry A (2011) Reefs at risk revisited. World Resources Institute, Washington, DC
Butler J (1980) Pink stripe on the ocean. Am Mus Nat Hist 89:62-63

Byler KA, Carmi-Veal M, Fine M, Goulet TL (2013) Multiple symbiont acquisition strategies as an adaptive mechanism in the coral Stylophora pistillata. PLOS ONE 8: e59596

* Cantin NE, van Oppen MJH, Willis BL, Mieog JC, Negri AP (2009) Juvenile corals can acquire more carbon from highperformance algal symbionts. Coral Reefs 28:405-414

Carpenter KE, Abrar M, Aeby G, Aronson RB and others (2008) One-third of reef-building corals face elevated extinction risk from climate change and local impacts. Science 321:560-563

* Chamberland VF, Vermeij MJA, Brittsan M, Carl M and others (2015) Restoration of critically endangered elkhorn coral (Acropora palmata) populations using larvae reared from wild-caught gametes. Glob Ecol Conserv 4: 526-537

Chamberland VF, Petersen D, Guest JR, Petersen U, Brittsan M, Vermeij MJA (2017) New seeding approach reduces costs and time to outplant sexually propagated corals for reef restoration. Sci Rep 7:18076

* Chua CM, Leggat W, Moya A, Baird AH (2013) Temperature affects the early life history stages of corals more than near future ocean acidification. Mar Ecol Prog Ser 475: 85-92

* Chui APY, Wong MC, Liu SH, Lee GW and others (2014) Gametogenesis, embryogenesis, and fertilization ecology of Platygyra acuta in marginal nonreefal coral communities in Hong Kong. J Mar Biol 2014:1-9

* Connell JH (1973) Population ecology of reef-building corals. In: Jones OA, Endean R (eds) Biology and geology of coral reefs, Vol II: Biology 1. Academic Press, New York, NY, p 205-245

Connolly SR, Baird AH (2010) Estimating dispersal potential for marine larvae: dynamic models applied to scleractinian corals. Ecology 91:3572-3583

* Cooper WT, Lirman D, VanGroningen MP, Parkinson JE, Herlan J, McManus JW (2014) Assessing techniques to enhance early post-settlement survival of corals in situ for reef restoration. Bull Mar Sci 90:651-664

Craggs J, Guest JR, Davis M, Simmons J, Dashti E, Sweet M (2017) Inducing broadcast coral spawning ex situ: closed system mesocosm design and husbandry protocol. Ecol Evol 7:11066-11078

* Craggs J, Guest J, Bulling M, Sweet M (2019) Ex situ co culturing of the sea urchin, Mespilia globulus and the coral Acropora millepora enhances early post-settlement survivorship. Sci Rep 9:12984

Cumbo VR, Baird AH, van Oppen MJH (2013) The promiscuous larvae: flexibility in the establishment of symbiosis in corals. Coral Reefs 32:111-120

* Cumbo V, van Oppen M, Baird AH (2018) Temperature and Symbiodinium physiology affect the establishment and development of symbiosis in corals. Mar Ecol Prog Ser 587:117-127

*Da-Anoy JP, Villanueva RD, Cabaitan PC, Conaco C (2017) Effects of coral extracts on survivorship, swimming behavior, and settlement of Pocillopora damicornis larvae. J Exp Mar Biol Ecol 486:93-97

* Damjanovic K, Blackall LL, Webster NS, Oppen MJH (2017) The contribution of microbial biotechnology to mitigating coral reef degradation. Microb Biotechnol 10:1236-1243

ํ. Davies SW, Matz MV, Vize PD (2013) Ecological complexity 
of coral recruitment processes: Effects of invertebrate herbivores on coral recruitment and growth depends upon substratum properties and coral species. PLOS ONE 8:e72830

Davies SW, Meyer E, Guermond SM, Matz MV (2014) A cross-ocean comparison of responses to settlement cues in reef-building corals. PeerJ 2:e333

Wavy SK, Allemand D, Weis VM (2012) Cell biology of cnidarian-dinoflagellate symbiosis. Microbiol Mol Biol Rev 76:229-261

De'ath G, Fabricius KE, Sweatman H, Puotinen M (2012) The 27-year decline of coral cover on the Great Barrier Reef and its causes. Proc Natl Acad Sci USA 109: 17995-17999

dela Cruz DW, Harrison PL (2017) Enhanced larval supply and recruitment can replenish reef corals on degraded reefs. Sci Rep 7:13985

Dixson DL, Abrego D, Hay ME (2014) Chemically mediated behavior of recruiting corals and fishes: a tipping point that may limit reef recovery. Science 345:892-897

Doropoulos C, Ward S, Diaz-Pulido G, Hoegh-Guldberg O, Mumby PJ (2012a) Ocean acidification reduces coral recruitment by disrupting intimate larval-algal settlement interactions: elevated $\mathrm{CO}_{2}$ alters CCA-larval interactions. Ecol Lett 15:338-346

Doropoulos C, Ward S, Marshell A, Diaz-Pulido G, Mumby PJ (2012b) Interactions among chronic and acute impacts on coral recruits: the importance of size-escape thresholds. Ecology 93:2131-2138

Doropoulos C, Roff G, Bozec YM, Zupan M, Werminghausen J, Mumby PJ (2016) Characterising the ecological trade-offs throughout the early ontogeny of coral recruitment. Ecol Monogr 86:20-44

Doropoulos C, Evensen NR, Gómez-Lemos LA, Babcock RC (2017) Density-dependent coral recruitment displays divergent responses during distinct early life-history stages. R Soc Open Sci 4:170082

Woropoulos C, Gómez-Lemos LA， Babcock RC (2018) Exploring variable patterns of density-dependent larval settlement among corals with distinct and shared functional traits. Coral Reefs 37:25-29

₹ Doropoulos C, Elzinga J, ter Hofstede R, van Koningsveld M, Babcock RC (2019) Optimizing industrial scale coral reef restoration: comparing harvesting wild coral spawn slicks and transplanting gravid adult colonies. Restor Ecol 27:758-767

* Doyle RW (1975) Settlement of planktonic larvae: a theory of habitat selection in varying environments. Am Nat 109: 113-126

* Drury C, Manzello D, Lirman D (2017) Genotype and local environment dynamically influence growth, disturbance response and survivorship in the threatened coral, Acropora cervicornis. PLOS ONE 12:e0174000

Edmunds PJ, Gates RD, Gleason DF (2001) The biology of larvae from the reef coral Porites astreoides, and their response to temperature disturbances. Mar Biol 139: 981-989

Edwards AJ (2010) Reef rehabilitation manual. Coral Reef Targeted Research \& Capacity Building for Management Program, St. Lucia, QLD

Edwards AJ, Gomez ED (2007) Reef restoration concepts \& guidelines: making sensible management choices in the face of uncertainty. Coral Reef Targeted Research \& Capacity Building for Management Program, St. Lucia, QLD
Edwards AJ, Guest JR, Heyward AJ, Villanueva RD, Baria MV, Bollozos ISF, Golbuu Y (2015) Direct seeding of mass-cultured coral larvae is not an effective option for reef rehabilitation. Mar Ecol Prog Ser 525: 105-116

Erwin PM, Szmant AM (2010) Settlement induction of Acropora palmata planulae by a GLW-amide neuropeptide. Coral Reefs 29:929-939

Eyal-Shaham L, Eyal G, Sakai K, Nozawa Y and others (2019) Repetitive sex change in the stony coral Herpolitha limax across a wide geographic range. Sci Rep 9:2936

Fabina NS, Putnam HM, Franklin EC, Stat M, Gates RD (2012) Transmission mode predicts specificity and interaction patterns in coral-Symbiodinium networks. PLOS ONE 7:e44970

Fabricius KE (2005) Effects of terrestrial runoff on the ecology of corals and coral reefs: review and synthesis. Mar Pollut Bull 50:125-146

Fabricius K, De'ath G, McCook L, Turak E, Williams DM (2005) Changes in algal, coral and fish assemblages along water quality gradients on the inshore Great Barrier Reef. Mar Pollut Bull 51:384-398

Fabricius KE, Kluibenschedl A, Harrington L, Noonan S, De'ath G (2015) In situ changes of tropical crustose coralline algae along carbon dioxide gradients. Sci Rep 5:9537

Fabricius KE, Noonan SHC, Abrego D, Harrington L, De'ath G (2017) Low recruitment due to altered settlement substrata as primary constraint for coral communities under ocean acidification. Proc R Soc B 284:20171536

Fadlallah YH (1983) Sexual reproduction, development and larval biology in scleractinian corals: a review. Coral Reefs 2:129-150

F Fan TY, Lin KH, Kuo FW, Soong K, Liu LL, Fang LS (2006) Diel patterns of larval release by five brooding scleractinian corals. Mar Ecol Prog Ser 321:133-142

* Feldman B, Shlesinger T, Loya Y (2018) Mesophotic coralreef environments depress the reproduction of the coral Paramontastraea peresi in the Red Sea. Coral Reefs 37: 201-214

Figueiredo J, Baird AH, Connolly SR (2013) Synthesizing larval competence dynamics and reef-scale retention reveals a high potential for self-recruitment in corals. Ecology 94:650-659

* Fogarty ND, Vollmer SV, Levitan DR (2012) Weak prezygotic isolating mechanisms in threatened Caribbean Acropora corals. PLOS ONE 7:e30486

* Forsman ZH, Rinkevich B, Hunter CL (2006) Investigating fragment size for culturing reef-building corals (Porites lobata and P. compressa) in ex situ nurseries. Aquaculture 261:89-97

Forsman ZH, Page CA, Toonen RJ, Vaughan D (2015) Growing coral larger and faster: micro-colony-fusion as a strategy for accelerating coral cover. PeerJ 3:e1313

Foster T, Gilmour JP (2016) Seeing red: Coral larvae are attracted to healthy-looking reefs. Mar Ecol Prog Ser 559: 65-71

Foster T, Gilmour J (2018) Reproduction of brooding corals at Scott Reef, Western Australia. Sci Matters 4: e201807000008

* Foster T, Gilmour JP, Chua CM, Falter JL, McCulloch MT (2015) Effect of ocean warming and acidification on the early life stages of subtropical Acropora spicifera. Coral Reefs 34:1217-1226

*Foster T, Heyward AJ, Gilmour JP (2018) Split spawning 
realigns coral reproduction with optimal environmental windows. Nat Commun 9:718

Gallagher C, Doropoulos C (2017) Spatial refugia mediate juvenile coral survival during coral-predator interactions. Coral Reefs 36:51-61

Garren M, Azam F (2012) Corals shed bacteria as a potential mechanism of resilience to organic matter enrichment. ISME J 6:1159-1165

*Gilmour JP, Smith LD, Brinkman RM (2009) Biannual spawning, rapid larval development and evidence of self-seeding for scleractinian corals at an isolated system of reefs. Mar Biol 156:1297-1309

* Gilmour JP, Underwood JN, Howells EJ, Gates E, Heyward AJ (2016) Biannual spawning and temporal reproductive isolation in Acropora corals. PLOS ONE 11:e0150916

Gleason DF, Hofmann DK (2011) Coral larvae: from gametes to recruits. J Exp Mar Biol Ecol 408:42-57

* Gleason DF, Danilowicz BS, Nolan CJ (2009) Reef waters stimulate substratum exploration in planulae from brooding Caribbean corals. Coral Reefs 28:549-554

Glynn PW, Gassman NJ, Eakin CM, Cortes J, Smith DB, Guzman HM (1991) Reef coral reproduction in the eastern Pacific: Costa Rica, Panama, and Galapagos Islands (Ecuador): I. Pocilloporidae. Mar Biol 109:355-368

Golbuu Y, Richmond RH (2007) Substratum preferences in planula larvae of two species of scleractinian corals, Goniastrea retiformis and Stylaraea punctata. Mar Biol 152:639-644

Golbuu Y, Wolanski E, Idechong JW, Victor S and others (2012) Predicting coral recruitment in Palau's complex reef archipelago. PLOS ONE 7:e50998

Goreau NI, Goreau TJ, Hayes RL (1981) Settling, survivorship and spatial aggregation in planulae and juveniles of the coral Porites porites (Pallas). Bull Mar Sci 31:424-435

Graham JE, van Woesik R (2013) The effects of partial mortality on the fecundity of three common Caribbean corals. Mar Biol 160:2561-2565

Graham EM, Baird AH, Connolly SR, Sewell MA, Willis BL (2017) Uncoupling temperature-dependent mortality from lipid depletion for scleractinian coral larvae. Coral Reefs 36:97-104

* Grasso LC, Negri AP, Fôret S, Saint R, Hayward DC, Miller DJ, Ball EE (2011) The biology of coral metamorphosis: molecular responses of larvae to inducers of settlement and metamorphosis. Dev Biol 353:411-419

Guest JR, Heyward AJ, Omori M, Iwao K, Morse A, Boch C (2010) Rearing coral larvae for reef rehabilitation. In: Edwards A (ed) Reef rehabilitation manual. Coral Reef Targeted Research \& Capacity Building for Management Program, St Lucia, QLD, p 73-98

* Guest JR, Baird AH, Goh BPL, Chou LM (2012) Sexual systems in scleractinian corals: an unusual pattern in the reef-building species Diploastrea heliopora. Coral Reefs 31:705-713

* Guest JR, Baria MV, Gomez ED, Heyward AJ, Edwards AJ (2014) Closing the circle: Is it feasible to rehabilitate reefs with sexually propagated corals? Coral Reefs 33: 45-55

* Guillemette R, Kaneko R, Blanton J, Tan J and others (2018) Bacterioplankton drawdown of coral mass-spawned organic matter. ISME J 12:2238-2251

Hall VR, Hughes TP (1996) Reproductive strategies of modular organisms: comparative studies of reef-building corals. Ecology 77:950-963
Hall NM, Berry KLE, Rintoul L, Hoogenboom MO (2015) Microplastic ingestion by scleractinian corals. Mar Biol 162:725-732

*Harii S, Omori M, Yamakawa H, Koike Y (2001) Sexual reproduction and larval settlement of the zooxanthellate coral Alveopora japonica Eguchi at high latitudes. Coral Reefs 20:19-23

Harrigan JF (1972) The planula larva of Pocillopora damicornis: lunar periodicity of swarming and substratum behavior. $\mathrm{PhD}$ dissertation, University of Hawaii, Honolulu

Harrington L, Fabricius K, De'ath G, Negri A (2004) Recognition and selection of settlement substrata determine post settlement survival in corals. Ecology 85:3428-3437

Harriott VJ (1983) Reproductive ecology of four scleratinian species at Lizard Island, Great Barrier Reef. Coral Reefs 2: 9-18

* Harriott VJ, Fisk DA (1987) A comparison of settlement plate types for experiments on the recruitment of scleractinian corals. Mar Ecol 37:201-208

Harrison PL (1985) Sexual characteristics of scleractinian corals: systematic and evolutionary implications. In: Gabrie C, Salvat B (eds) Proc 5th Int Coral Reef Congress, Vol 4, Moorea, p 337-342

Harrison PL (2006) Settlement competency periods and dispersal potential of scleractinian reef coral larvae. In: Suzuki Y, Nakamori T, Hidaka M, Kayanne H and others (eds) Proc 10th Int Coral Reef Symp, Okinawa, p 78-82

Harrison PL (2011) Sexual reproduction of scleractinian corals. In: Dubinsky Z, Stambler N (eds) Coral reefs: an ecosystem in transition. Springer, Dordrecht, p 59-85

Harrison PL, Wallace CC (1990) Reproduction, dispersal and recruitment of scleractinian corals. Ecosyst World 25: 133-207

*Harrison PL, Babcock RC, Bull GD, Oliver JK, Wallace CC, Willis BL (1984) Mass spawning in tropical reef corals. Science 223:1186-1189

Harrison P, Villanueva R, de la Cruz D (2016) Coral reef restoration using mass coral larval reseeding. Australian Centre for International Agricultural Research, Bruce, ACT. www.aciar.gov.au/project/FIS-2014-063

* Harvell CD, Grosberg RK (1988) The timing of sexual maturity in clonal animals. Ecology 69:1855-1864

*Hata T, Madin JS, Cumbo VR, Denny M and others (2017) Coral larvae are poor swimmers and require fine-scale reef structure to settle. Sci Rep 7:2249

*Hayashibara T, Shimoike K, Kimura T, Hosaka S and others (1993) Patterns of coral spawning at Akajima Island, Okinawa, Japan. Mar Ecol Prog Ser 101:253-262

Hayashibara T, Ohike S, Kakinuma Y (1997) Embryonic and larval development and planula metamorphosis of four gamete-spawning Acropora (Anthozoa, Scleractinia). In: Lessios HA, Macintyre IG (eds) Proc 8th Int Coral Reef Symp, Vol 2. Smithsonian Tropical Research Institute, Panama, p 1231-1236

*Hayashibara T, Iwao K, Omori M (2004) Induction and control of spawning in Okinawan staghorn corals. Coral Reefs 23:406-409

* Hein MY, Willis BL, Beeden R, Birtles A (2017) The need for broader ecological and socioeconomic tools to evaluate the effectiveness of coral restoration programs: socioecological effectiveness of coral restoration revisited. Restor Ecol 25:873-883

Heyward AJ (1987) Genetic systems and hereditary structures of reef corals. PhD dissertation, James Cook University, Townsville, QLD 
Heyward AJ, Collins JD (1985) Fragmentation in Montipora ramosa: the genet and ramet concept applied to a reef coral. Coral Reefs 4:35-40

*Heyward AJ, Negri AP (1999) Natural inducers for coral larval metamorphosis. Coral Reefs 18:273-279

Heyward AJ, Negri AP (2010) Plasticity of larval pre-competency in response to temperature: observations on multiple broadcast spawning coral species. Coral Reefs 29: 631-636

Heyward AJ, Negri AP (2012) Turbulence, cleavage, and the naked embryo: a case for coral clones. Science 335:1064

Heyward AJ, Stoddart JA (1985) Genetic structure of two species of Montipora on a patch reef: conflicting results from electrophoresis and histocompatibility. Mar Biol 85: $117-121$

Heyward AJ, Rees M, Smith LD (1999) Coral spawning slicks harnessed for large-scale coral culture. In: International Conference on Scientific Aspects of Coral Reef Assessment, Monitoring and Restoration. National Coral Reef Institute, Nova Southeastern University, Fort Lauderdale, FL

Heyward AJ, Smith LD, Rees M, Field SN (2002) Enhancement of coral recruitment by in situ mass culture of coral larvae. Mar Ecol Prog Ser 230:113-118

Hidaka M (1985) Tissue compatibility between colonies and between newly settled larvae of Pocillopora damicornis. Coral Reefs 4:111-116

*Hidaka M, Yurugi K, Sunagawa S, Kinzie RA III (1997) Contact reactions between young colonies of the coral Pocillopora damicornis. Coral Reefs 16:13-20

Higa Y, Omori M (2014) Production of coral colonies for outplanting using a unique rearing method of donor colonies at Onna Village, Okinawa, Japan. Galaxea J Coral Reef Stud 16:19-20

Hoadley KD, Vize PD, Pyott SJ (2016) Current understanding of the circadian clock within Cnidaria. In: Goffredo S, Dubinsky Z (eds) The Cnidaria, past, present and future. Springer, Cham, p 511-520

KHowells EJ, Abrego D, Meyer E, Kirk NL, Burt JA (2016a) Host adaptation and unexpected symbiont partners enable reef building corals to tolerate extreme temperatures. Glob Change Biol 22:2702-2714

Howells EJ, Ketchum RN, Bauman AG, Mustafa Y, Watkins KD, Burt JA (2016b) Species-specific trends in the reproductive output of corals across environmental gradients and bleaching histories. Mar Pollut Bull 105:532-539

* Hudspith M, Reichelt-Brushett A, Harrison PL (2017) Factors affecting the toxicity of trace metals to fertilization success in broadcast spawning marine invertebrates: a review. Aquat Toxicol 184:1-13

Hughes TP, Barnes ML, Bellwood DR, Cinner JE and others (2017) Coral reefs in the Anthropocene. Nature 546: 82-90

Hughes TP, Anderson KD, Connolly SR, Heron SF and others (2018) Spatial and temporal patterns of mass bleaching of corals in the Anthropocene. Science 359: 80-83

Humanes A, Ricardo GF, Willis BL, Fabricius KE, Negri AP (2017) Cumulative effects of suspended sediments, organic nutrients and temperature stress on early life history stages of the coral Acropora tenuis. Sci Rep 7: 44101

Hume BCC, D'Angelo C, Smith EG, Stevens JR, Burt J, Wiedenmann J (2015) Symbiodinium thermophilum sp. nov., a thermotolerant symbiotic alga prevalent in corals of the world's hottest sea, the Persian/Arabian Gulf. Sci Rep 5:8562

*Humphrey C, Weber M, Lott C, Cooper T, Fabricius K (2008) Effects of suspended sediments, dissolved inorganic nutrients and salinity on fertilisation and embryo development in the coral Acropora millepora (Ehrenberg, 1834). Coral Reefs 27:837-850

Huston M (1985) Variation in coral growth rates with depth at Discovery Bay, Jamaica. Coral Reefs 4:19-25

Iglesias-Prieto R, Beltran VH, LaJeunesse TC, Reyes-Bonilla H, Thomé PE (2004) Different algal symbionts explain the vertical distribution of dominant reef corals in the eastern Pacific. Proc R Soc B 271:1757-1763

* Iwao K, Fujisawa T, Hatta M (2002) Acnidarian neuropeptide of the GLWamide family induces metamorphosis of reef-building corals in the genus Acropora. Coral Reefs 21:127-129

Jackson JBC, Hughes TP (1985) Adaptive strategies of coralreef invertebrates: Coral-reef environments that are regularly disturbed by storms and by predation often favor the very organisms most susceptible to damage by these processes. Am Sci 73:265-274

Jamodiong EA, Maboloc EA, Leriorato JC, Tañedo MCS and others (2018) Coral spawning and spawn-slick observation in the Philippines. Mar Biodivers 48:2187-2192

Jiang L, Lei XM, Liu S, Huang H (2015) Fused embryos and pre-metamorphic conjoined larvae in a broadcast spawning reef coral. F1000 Res 4:44

Johnson ME, Lustic C, Bartels E, Gilliam DS and others (2011) Caribbean Acropora restoration guide: best practices for propagation and population enhancement. Nature Conservancy, Arlington, VA

Jokiel PL, Ito RY, Liu PM (1985) Night irradiance and synchronization of lunar release of planula larvae in the reef coral Pocillopora damicornis. Mar Biol 88:167-174

Jones A, Berkelmans R (2010) Potential costs of acclimatization to a warmer climate: growth of a reef coral with heat tolerant vs. sensitive symbiont types. PLOS ONE 5:e10437

Jones AT, Thankappan M, Logan GA, Kennard JM, Smith CJ, Williams AK, Lawrence GM (2006) Coral spawn and bathymetric slicks in Synthetic Aperture Radar (SAR) data from the Timor Sea, north west Australia. Int J Remote Sens 27:2063-2069

Jones R, Ricardo GF, Negri AP (2015) Effects of sediments on the reproductive cycle of corals. Mar Pollut Bull 100:13-33

Kai S, Sakai K (2008) Effect of colony size and age on resource allocation between growth and reproduction in the corals Goniastrea aspera and Favites chinensis. Mar Ecol Prog Ser 354:133-139

Kaniewska P, Alon S, Karako-Lampert S, Hoegh-Guldberg O, Levy O (2015) Signaling cascades and the importance of moonlight in coral broadcast mass spawning. eLife 4: e09991

Kawaguti S (1940) An abundance of reef-coral planulae in the plankton. Zool Mag 52:31

Keith SA, Maynard JA, Edwards AJ, Guest JR and others (2016) Coral mass spawning predicted by rapid seasonal rise in ocean temperature. Proc R Soc B 283:20160011

Kitamura M, Koyama T, Nakano Y, Uemura D (2007) Characterization of a natural inducer of coral larval metamorphosis. J Exp Mar Biol Ecol 340:96-102

Kitamura M, Schupp PJ, Nakano Y, Uemura D (2009) Luminaolide, a novel metamorphosis-enhancing macrodiolide for scleractinian coral larvae from crustose coralline algae. Tetrahedron Lett 50:6606-6609 
Kojis BL (1986) Sexual reproduction in Acropora (Isopora) (Coelenterata: Scleractinia): II. Latitudinal variation in $A$. palifera from the Great Barrier Reef and Papua New Guinea. Mar Biol 91:311-318

Kojis BL, Quinn NJ (1981) Aspects of sexual reproduction and larval development in the shallow water hermatypic coral, Goniastrea australensis (Edwards and Haime, 1857). Bull Mar Sci 31:558-573

Kojis BL, Quinn NJ (1984) Seasonal and depth variation in fecundity of Acropora palifera at two reefs in Papua New Guinea. Coral Reefs 3:165-172

Kojis BL, Quinn NJ (1985) Puberty in Goniastrea favulus: age or size limited? In: Gabrie C, Salvat B (eds) Proc 5th Int Coral Reef Congress, Vol 4, Tahiti, p 289-293

Kuffner IB, Andersson AJ, Jokiel PL, Rodgers KS, Mackenzie FT (2008) Decreased abundance of crustose coralline algae due to ocean acidification. Nat Geosci 1:114-117

Ladd MC, Miller MW, Hunt JH, Sharp WC, Burkepile DE (2018) Harnessing ecological processes to facilitate coral restoration. Front Ecol Environ 16:239-247

KaJeunesse TC, Parkinson JE, Gabrielson PW, Jeong HJ, Reimer JD, Voolstra CR, Santos SR (2018) Systematic revision of Symbiodiniaceae highlights the antiquity and diversity of coral endosymbionts. Curr Biol 28: 2570-2580

Lam EKY, Chui APY, Kwok CK, Ip AHP and others (2015) High levels of inorganic nutrients affect fertilization kinetics, early development and settlement of the scleractinian coral Platygyra acuta. Coral Reefs 34:837-848

Lamb JB, Willis BL, Fiorenza EA, Couch CS and others (2018) Plastic waste associated with disease on coral reefs. Science 359:460-462

* Leite DCA, Leão P, Garrido AG, Lins U and others (2017) Broadcast spawning coral Mussismilia hispida can vertically transfer its associated bacterial core. Front Microbiol 8:176

Leuzinger S, Anthony KRN, Willis BL (2003) Reproductive energy investment in corals: scaling with module size. Oecologia 136:524-531

* Levy O, Appelbaum L, Leggat W, Gothlif Y, Hayward DC, Miller DJ, Hoegh-Guldberg O (2007) Light-responsive cryptochromes from a simple multicellular animal, the coral Acropora millepora. Science 318:467-470

Lewis JB (1974) Settlement behavior of planulae larvae of hermatypic coral Favia fragum (Esper). J Exp Mar Biol Ecol 15:165-172

* Linden B, Huisman J, Rinkevich B (2018) Circatrigintan instead of lunar periodicity of larval release in a brooding coral species. Sci Rep 8:5668

Lirman D (2000) Fragmentation in the branching coral Acropora palmata (Lamarck): growth, survivorship, and reproduction of colonies and fragments. J Exp Mar Biol Ecol 251:41-57

Lirman D, Schopmeyer S (2016) Ecological solutions to reef degradation: optimizing coral reef restoration in the Caribbean and Western Atlantic. PeerJ 4:e2597

Little AF, van Oppen MJH, Willis BL (2004) Flexibility in algal endosymbioses shapes growth in reef corals. Science 304:1492-1494

* Lough JM, Barnes DJ (2000) Environmental controls on growth of the massive coral Porites. J Exp Mar Biol Ecol 245:225-243

Lough JM, Anderson KD, Hughes TP (2018) Increasing thermal stress for tropical coral reefs: 1871-2017. Sci Rep 8: 6079
Loya Y (1976) The Red Sea coral Stylophora pistillata is an $r$ strategist. Nature 259:478-480

Loya Y, Sakai K, Heyward A (2009) Reproductive patterns of fungiid corals in Okinawa, Japan. Galaxea J Coral Reef Stud 11:119-129

MacArthur RH, Wilson EO (1967) The theory of island biogeography. Princeton University Press, Princeton, NJ

Madin JS, Anderson KD, Andreasen MH, Bridge TCL and others (2016) The Coral Trait Database, a curated database of trait information for coral species from the global oceans. Sci Data 3:160017

* Madsen A, Madin JS, Tan CH, Baird AH (2014) The reproductive biology of the scleractinian coral Plesiastrea versipora in Sydney Harbour, Australia. Sex Early Dev Aquat Org 1:25-33

*Mangubhai S, Harrison PL (2008a) Gametogenesis, spawning and fecundity of Platygyra daedalea (Scleractinia) on equatorial reefs in Kenya. Coral Reefs 27:117-122

Mangubhai S, Harrison PL (2008b) Asynchronous coral spawning patterns on equatorial reefs in Kenya. Mar Ecol Prog Ser 360:85-96

*Mangubhai S, Harris A, Graham NAJ (2007) Synchronous daytime spawning of the solitary coral Fungia danai (Fungiidae) in the Chagos Archipelago, central Indian Ocean. Coral Reefs 26:15

Mason B, Beard M, Miller MW (2011) Coral larvae settle at a higher frequency on red surfaces. Coral Reefs 30:667-676

Mieog JC, Olsen JL, Berkelmans R, Bleuler-Martinez SA, Willis BL, van Oppen MJH (2009) The roles and interactions of symbiont, host and environment in defining coral fitness. PLOS ONE 4:e6364

* Mizrahi D, Navarrete SA, Flores AAV (2014) Uneven abundance of the invasive sun coral over habitat patches of different orientation: an outcome of larval or later benthic processes? J Exp Mar Biol Ecol 452:22-30

Mohammed JS (2016) Applications of 3D printing technologies in oceanography. Methods Oceanogr 17:97-117

* Morrow KM, Bromhall K, Motti CA, Munn CB, Bourne DG (2016) Allelochemicals produced by the brown macroalga, Lobophora sp., are active against coral larvae and associated bacteria, supporting pathogenic shifts to Vibrio dominance. Appl Environ Microbiol 83: e02391-16

Morse DE, Morse ANC (1991) Enzymatic characterization of the morphogen recognized by Agaricia humilis (scleractinian coral) larvae. Biol Bull 181:104-122

Morse DE, Hooker N, Morse ANC, Jensen RA (1988) Control of larval metamorphosis and recruitment in sympatric agariciid corals. J Exp Mar Biol Ecol 116:193-217

* Morse DE, Morse ANC, Raimondi PT, Hooker N (1994) Morphogen-based chemical flypaper for Agaricia humilis coral larvae. Biol Bull 186:172-181

* Morse A, Iwao K, Baba M, Shimoike K, Hayashibara T, Omori M (1996) An ancient chemosensory mechanism brings new life to coral reefs. Biol Bull 191:149-154

*Mumby PJ (1999) Bleaching and hurricane disturbances to populations of coral recruits in Belize. Mar Ecol Prog Ser 190:27-35

Mundy CN, Babcock RC (1998) Role of light intensity and spectral quality in coral settlement: implications for depth-dependent settlement? J Exp Mar Biol Ecol 223: 235-255

*Muscatine L, Porter JW (1977) Reef corals: mutualistic symbioses adapted to nutrient-poor environments. Bioscience 27:454-460 
Nakamura R, Ando W, Yamamoto H, Kitano M and others (2011) Corals mass-cultured from eggs and transplanted as juveniles to their native, remote coral reef. Mar Ecol Prog Ser 436:161-168

National Academies of Sciences, Engineering, and Medicine (2019) A research review of interventions to increase the persistence and resilience of coral reefs. National Academies Press, Washington, DC

Negri AP, Heyward AJ (2000) Inhibition of fertilization and larval metamorphosis of the coral Acropora millepora (Ehrenberg, 1834) by petroleum products. Mar Pollut Bull 41:420-427

Negri AP, Webster NS, Hill RT, Heyward AJ (2001) Metamorphosis of broadcast spawning corals in response to bacteria isolated from crustose algae. Mar Ecol Prog Ser 223:121-131

Negri A, Vollhardt C, Humphrey C, Heyward A, Jones R, Eaglesham G, Fabricius K (2005) Effects of the herbicide diuron on the early life history stages of coral. Mar Pollut Bull 51:370-383

Negri AP, Marshall PA, Heyward AJ (2007) Differing effects of thermal stress on coral fertilization and early embryogenesis in four Indo Pacific species. Coral Reefs 26: 759-763

Ng CSL, Toh TC, Chou LM (2016) Coral restoration in Singapore's sediment-challenged sea. Reg Stud Mar Sci 8: 422-429

Nietzer S, Moeller M, Kitamura M, Schupp PJ (2018) Coral larvae every day: Leptastrea purpurea, a brooding species that could accelerate coral research. Front Mar Sci 5: 466

Nitschke MR, Gardner SG, Goyen S, Fujise L, Camp EF, Ralph PJ, Suggett DJ (2018) Utility of photochemical traits as diagnostics of thermal tolerance amongst Great Barrier Reef corals. Front Mar Sci 5:45

Noreen AME, Harrison PL, van Oppen MJH (2009) Genetic diversity and connectivity in a brooding reef coral at the limit of its distribution. Proc R Soc B 276:3927-3935

*Nozawa Y (2008) Micro-crevice structure enhances coral spat survivorship. J Exp Mar Biol Ecol 367:127-130

Nozawa Y (2012) Annual variation in the timing of coral spawning in a high-latitude environment: influence of temperature. Biol Bull 222:192-202

Nozawa Y, Harrison PL (2000) Larval settlement patterns, dispersal potential, and the effect of temperature on settlement of larvae of the reef coral, Platygyra daedalea, from the Great Barrier Reef. In: Moosa MK, Soemodihardjo S, Soegiarto A, Romimohtarto K, Nontji A, Soekarno, Suharsono (eds) Proc 9th Int Coral Reef Symp, Bali, p 409-416

Nozawa Y, Harrison PL (2007) Effects of elevated temperature on larval settlement and post-settlement survival in scleractinian corals, Acropora solitaryensis and Favites chinensis. Mar Biol 152:1181-1185

Nozawa Y, Lin CH (2014) Effects of colony size and polyp position on polyp fecundity in the scleractinian coral genus Acropora. Coral Reefs 33:1057-1066

Nozawa Y, Loya Y (2005) Genetic relationship and maturity state of the allorecognition system affect contact reactions in juvenile Seriatopora corals. Mar Ecol Prog Ser 286:115-123

K Okamoto M, Nojima S, Fujiwara S, Furushima Y (2008) Development of ceramic settlement devices for coral reef restoration using in situ sexual reproduction of corals. Fish Sci 74:1245-1253
Okubo N, Motokawa T (2007) Embryogenesis in the reefbuilding coral Acropora spp. Zool Sci 24:1169-1177

* Okubo N, Motokawa T, Omori M (2007) When fragmented coral spawn? Effect of size and timing on survivorship and fecundity of fragmentation in Acropora formosa. Mar Biol 151:353-363

* Okubo N, Mezaki T, Nozawa Y, Nakano Y and others (2013) Comparative embryology of eleven species of stony corals (Scleractinia). PLOS ONE 8:e84115

* Okubo N, Toshino S, Nakano Y, Yamamoto HH (2017) Coral individuality-confluence of change physical splitting and developmental ability of embryos. Sci Rep 7:16006

Oliver JK, Willis BL (1987) Coral-spawn slicks in the Great Barrier Reef: preliminary observations. Mar Biol 94: 521-529

Oliver JK, Babcock RC, Harrison PL, Willis BL (1988) Geographical extent of mass spawning: clues to ultimate causal factors. In: Choat JH (ed) Proc 6th Int Coral Reef Symp, Townsville, QLD, p 803-810

\% Omori M (2005) Success of mass culture of Acropora corals from egg to colony in open water. Coral Reefs 24:563

* Omori M (2019) Coral restoration research and technical developments: what we have learned so far. Mar Biol Res 15:377-409

Omori M, Fujiwara S (2004) Manual for restoration and remediation of coral reefs. Nature Conservation Bureau, Ministry of the Environment, Tokyo

Omori M, Iwao K (2014) Methods of farming sexually propagated corals and outplanting for coral reef rehabilitation; with list of references for coral reef rehabilitation through active restoration measure. Akajima Marine Science Laboratory, Okinawa

Omori M, Aota T, Watanuki A, Toniguchi H (2004) Development of coral restoration method by mass culture, transplantation and settlement of coral larvae. In: Proc 1st Coral Reef Conf, Palau, p 30-38

\% Omori M, Kubo H, Kajiwara K, Matsumoto H, Watanuki A (2006) Rapid recruitment of corals on top shell snail aquaculture structures. Coral Reefs 25:280

* Oren U, Benayahu Y, Lubinevsky H, Loya Y (2001) Colony integration during regeneration in the stony coral Favia favus. Ecology 82:802-813

* Ortiz JC, Wolff NH, Anthony KRN, Devlin M, Lewis S, Mumby PJ (2018) Impaired recovery of the Great Barrier Reef under cumulative stress. Sci Adv 4:eaar6127

O Osborne K, Thompson AA, Cheal AJ, Emslie MJ and others (2017) Delayed coral recovery in a warming ocean. Glob Change Biol 23:3869-3881

*Page CA, Muller EM, Vaughan DE (2018) Microfragmenting for the successful restoration of slow growing massive corals. Ecol Eng 123:86-94

* Pandolfi JM, Bradbury RH, Sala E, Hughes TP and others (2003) Global trajectories of the long-term decline of coral reef ecosystems. Science 301:955-958

*Penland L, Kloulechad J, Idip D, van Woesik R (2004) Coral spawning in the western Pacific Ocean is related to solar insolation: evidence of multiple spawning events in Palau. Coral Reefs 23:133-140

* Petersen D, Laterveer M, Schuhmacher H (2005) Innovative substrate tiles to spatially control larval settlement in coral culture. Mar Biol 146:937-942

* Poland DM, Coffroth MA (2017) Trans-generational specificity within a cnidarian-algal symbiosis. Coral Reefs 36 : 119-129 
Pollock FJ, Katz SM, van de Water JAJM, Davies SW and others (2017) Coral larvae for restoration and research: a large-scale method for rearing Acropora millepora larvae, inducing settlement, and establishing symbiosis. PeerJ 5:e3732

Puill-Stephan E, Willis BL, van Herwerden L, van Oppen MJH (2009) Chimerism in wild adult populations of the broadcast spawning coral Acropora millepora on the Great Barrier Reef. PLOS ONE 4:e7751

Puill-Stephan E, Willis BL, Abrego D, Raina JB, van Oppen MJH (2012a) Allorecognition maturation in the broadcast-spawning coral Acropora millepora. Coral Reefs 31: 1019-1028

Puill-Stephan E, van Oppen MJH, Pichavant-Rafini K, Willis BL (2012b) High potential for formation and persistence of chimeras following aggregated larval settlement in the broadcast spawning coral, Acropora millepora. Proc R Soc B 279:699-708

Putnam HM, Gates RD (2015) Preconditioning in the reefbuilding coral Pocillopora damicornis and the potential for trans-generational acclimatization in coral larvae under future climate change conditions. J Exp Biol 218: 2365-2372

* Putnam HM, Edmunds PJ, Fan TY (2008) Effect of temperature on the settlement choice and photophysiology of larvae from the reef coral Stylophora pistillata. Biol Bull 215:135-142

Quigley KM, Willis BL, Bay LK (2016) Maternal effects and Symbiodinium community composition drive differential patterns in juvenile survival in the coral Acropora tenuis. R Soc Open Sci 3:160471

* Quigley K, Willis B, Bay L (2017a) Heritability of the Symbiodinium community in vertically- and horizontally-transmitting broadcast spawning corals. Sci Rep $7: 8219$

* Quigley KM, Bay LK, Willis BL (2017b) Temperature and water quality-related patterns in sediment-associated Symbiodinium communities impact symbiont uptake and fitness of juveniles in the genus Acropora. Front Mar Sci $4: 401$

* Quigley KM, Warner PA, Bay LK, Willis BL (2018a) Unexpected mixed-mode transmission and moderate genetic regulation of Symbiodinium communities in a brooding coral. Heredity 121:524-536

Quigley KM, Torda G, Bay LK (2018b) The use of larvae or recruits in coral restoration initiatives: Symbiodinium acquisition does not differ between coral life stages in the wild: Symbiodinium uptake for restoration practices. Restor Ecol 26:422-425

* Quigley KM, Willis BL, Kenkel CD (2019) Transgenerational inheritance of shuffled symbiont communities in the coral Montipora digitata. Sci Rep 9:13328

Raimondi PT, Morse ANC (2000) The consequences of complex larval behavior in a coral. Ecology 81:3193-3211

* Randall CJ, Szmant AM (2009a) Elevated temperature affects development, survivorship, and settlement of the elkhorn coral, Acropora palmata (Lamarck 1816). Biol Bull 217:269-282

Randall CJ, Szmant AM (2009b) Elevated temperature reduces survivorship and settlement of the larvae of the Caribbean scleractinian coral, Favia fragum (Esper). Coral Reefs 28:537-545

Raymundo LJ, Maypa AP (2004) Getting bigger faster: mediation of size-specific mortality via fusion in juvenile coral transplants. Ecol Appl 14:281-295
Reich HG, Robertson DL, Goodbody-Gringley G (2017) Do the shuffle: changes in Symbiodinium consortia throughout juvenile coral development. PLOS ONE 12:e0171768

Reichelt-Brushett AJ, Harrison PL (2000) The effect of copper on the settlement success of larvae from the scleractinian coral Acropora tenuis. Mar Pollut Bull 41:385-391

Keichert J, Schellenberg J, Schubert P, Wilke T (2018) Responses of reef building corals to microplastic exposure. Environ Pollut 237:955-960

* Reynolds JM, Bruns BU, Fitt WK, Schmidt GW (2008) Enhanced photoprotection pathways in symbiotic dinoflagellates of shallow-water corals and other cnidarians. Proc Natl Acad Sci USA 105:13674-13678

Ricardo GF, Jones RJ, Nordborg M, Negri AP (2017) Settlement patterns of the coral Acropora millepora on sediment-laden surfaces. Sci Total Environ 609:277-288

* Richmond RH (1987) Energetics, competency, and long-distance dispersal of planula larvae of the coral Pocillopora damicornis. Mar Biol 93:527-533

Richmond RH (1993) Coral reefs: present problems and future concerns resulting from anthropogenic disturbance. Am Zool 33:524-536

* Richmond R, Hunter C (1990) Reproduction and recruitment of corals: comparisons among the Caribbean, the Tropical Pacific, and the Red Sea. Mar Ecol Prog Ser 60: 185-203

* Richmond RH, Tisthammer KH, Spies NP (2018) The effects of anthropogenic stressors on reproduction and recruitment of corals and reef organisms. Front Mar Sci $5: 226$

* Rinkevich B (1996) Do reproduction and regeneration in damaged corals compete for energy allocation? Mar Ecol Prog Ser 143:297-302

* Rinkevich B (2005) Conservation of coral reefs through active restoration measures: recent approaches and last decade progress. Environ Sci Technol 39:4333-4342

Kinkevich B (2008) Management of coral reefs: We have gone wrong when neglecting active reef restoration. Mar Pollut Bull 56:1821-1824

* Rinkevich B, Loya Y (1985) Intraspecific competition in a reef coral: effects on growth and reproduction. Oecologia 66:100-105

Rinkevich B, Weissman IL (1987) Chimeras in colonial invertebrates: a synergistic symbiosis or somatic-and germcell parasitism. Symbiosis 4:117-134

* Rinkevich B, Weissman IL (1992) Chimeras vs genetically homogeneous individuals: potential fitness costs and benefits. Oikos 63:119-124

* Rinkevich B, Shaish L, Douek J, Ben-Shlomo R (2016) Venturing in coral larval chimerism: a compact functional domain with fostered genotypic diversity. Sci Rep 6:19493

* Ritson-Williams R, Paul VJ, Arnold SN, Steneck RS (2010) Larval settlement preferences and post-settlement survival of the threatened Caribbean corals Acropora palmata and A. cervicornis. Coral Reefs 29:71-81

Kitson-Williams R, Arnold SN, Paul VJ (2016) Patterns of larval settlement preferences and post-settlement survival for seven Caribbean corals. Mar Ecol Prog Ser 548: $127-138$

Roberts CM (1997) Connectivity and management of Caribbean coral reefs. Science 278:1454-1457

Komano JC (1996) Sea-surface slick occurrence in the open sea (Mediterranean, Red Sea, Indian Ocean) in relation to wind speed. Deep Sea Res I 43:411-423 
Romano JC, Marquet R (1991) Occurrence frequencies of sea-surface slicks at long and short time-scales in relation to wind speed. Estuar Coast Shelf Sci 33: 445-458

Rosado PM, Leite DCA, Duarte GAS, Chaloub RM and others (2018) Marine probiotics: increasing coral resistance to bleaching through microbiome manipulation. ISME J 13:921-936

Sakai K (1998) Delayed maturation in the colonial coral Goniastrea aspera (Scleractinia): whole-colony mortality, colony growth and polyp egg production. Res Popul Ecol (Kyoto) 40:287-292

Selig ER, Casey KS, Bruno JF (2012) Temperature-driven coral decline: the role of marine protected areas. Glob Change Biol 18:1561-1570

Shaish L, Levy G, Katzir G, Rinkevich B (2010) Employing a highly fragmented, weedy coral species in reef restoration. Ecol Eng 36:1424-1432

Sharp KH, Distel D, Paul VJ (2012) Diversity and dynamics of bacterial communities in early life stages of the Caribbean coral Porites astreoides. ISME J 6:790-801

* Sharp KH, Sneed JM, Ritchie KB, Mcdaniel L, Paul VJ (2015) Induction of larval settlement in the reef coral Porites astreoides by a cultivated marine Roseobacter strain. Biol Bull 228:98-107

Sherman CDH (2008) Mating system variation in the hermaphroditic brooding coral, Seriatopora hystrix. Heredity 100:296-303

Shlesinger Y, Loya Y (1985) Coral community reproductive patterns: Red Sea versus the Great Barrier Reef. Science 228:1333-1335

Shlesinger T, Grinblat M, Rapuano H, Amit T, Loya Y (2018) Can mesophotic reefs replenish shallow reefs? Reduced coral reproductive performance casts a doubt. Ecology 99:421-437

Simpson CJ, Cary JL, Masini RJ (1993) Destruction of corals and other reef animals by coral spawn slicks on Ningaloo Reef, Western Australia. Coral Reefs 12:185-191

Smith LD, Hughes TP (1999) An experimental assessment of survival, re-attachment and fecundity of coral fragments. J Exp Mar Biol Ecol 235:147-164

* Sneed JM, Sharp KH, Ritchie KB, Paul VJ (2014) The chemical cue tetrabromopyrrole from a biofilm bacterium induces settlement of multiple Caribbean corals. Proc R Soc B 281:20133086

Soong K (1993) Colony size as a species character in massive reef corals. Coral Reefs 12:77-83

Soong K, Lang JC (1992) Reproductive integration in reef corals. Biol Bull 183:418-431

* Sorek M, Díaz-Almeyda EM, Medina M, Levy O (2014) Circadian clocks in symbiotic corals: the duet between Symbiodinium algae and their coral host. Mar Genomics 14: 47-57

Spadaro AJ (2014) Caribbean coral reef restoration: a brief review and concept proposal of a new method. In: 67th Annual Conference of the Gulf and Caribbean Fisheries Institute, Christ Church, Barbados. Gulf and Caribbean Fisheries Institute, Ft. Pierce, FL, p 374-377

Spieler RE, Gilliam DS, Sherman RL (2001) Artificial substrate and coral reef restoration: What do we need to know to know what we need. Bull Mar Sci 69:1013-1030

Stake JL, Sammarco PW (2003) Effects of pressure on swimming behavior in planula larvae of the coral Porites astreoides (Cnidaria, Scleractinia). J Exp Mar Biol Ecol 288:181-201
Stephenson TA (1931) Development and the formation of colonies in Pocillopora and Porites, Part I. In: Great Barrier Reef expedition 1928-29 scientific reports, Vol 3. British Museum (Natural History), London, p 113-134

Stobart B, Babcock RC, Willis BL (1992) Biannual spawning of three species of scleractinian coral from the Great Barrier Reef. In: Richmond $\mathrm{RH}$ (ed) Proc 7th Int Coral Reef Symp, Vol 1. International Society of Reef Studies, Guam, p 494-499

Stoddart JA, Ayre DJ, Willis B, Heyward AJ (1985) Selfrecognition in sponges and corals? Evolution 39: 461-463

Strader ME, Davies SW, Matz MV (2015) Differential responses of coral larvae to the colour of ambient light guide them to suitable settlement microhabitat. R Soc Open Sci 2:150358

* Sunagawa S, Woodley CM, Medina M (2010) Threatened corals provide underexplored microbial habitats. PLOS ONE 5:e9554

* Suzuki G, Kai S, Yamashita H, Suzuki K, Iehisa Y, Hayashibara $T$ (2011) Narrower grid structure of artificial reef enhances initial survival of in situ settled coral. Mar Pollut Bull 62:2803-2812

* Suzuki G, Arakaki S, Suzuki K, Iehisa Y, Hayashibara T (2012) What is the optimal density of larval seeding in Acropora corals? Fish Sci 78:801-808

* Suzuki G, Wataru O, Yasutke Y, Kai S and others (2018) Interspecific differences in the post-settlement survival of Acropora corals under a common garden experiment. Fish Sci 84:849-856

Sweet MJ, Brown BE (2016) Coral responses to anthropogenic stress in the 21st century - an ecophysiological perspective. Oceanogr Mar Biol Annu Rev 54:271-314

* Szmant AM (1986) Reproductive ecology of Caribbean reef corals. Coral Reefs 5:43-53

Szmant AM, Meadows MG (2006) Developmental changes in coral larval buoyancy and vertical swimming behavior: implications for dispersal and connectivity. In: Proc 10th Int Coral Reef Symp. International Society for Reef Studies, Okinawa, p 431-437

Szmant-Froelich A (1985) The effect of colony size on the reproductive ability of the Caribbean coral Montastrea annularis (Ellis and Solander). In: Gabrie C, Salvat B (eds) Proc 5th Int Coral Reef Symp, Vol 4, Tahiti, p 295-300

Szmant-Froelich A, Yevich P, Pilson MEQ (1980) Gametogenesis and early development of the temperate coral Astrangia danae (Anthozoa: Scleractinia). Biol Bull 158: 257-269

Tanner JE (1995) Competition between scleractinian corals and macroalgae: an experimental investigation of coral growth, survival and reproduction. J Exp Mar Biol Ecol 190:151-168

Tay YC, Guest JR, Chou LM, Todd PA (2011) Vertical distribution and settlement competencies in broadcast spawning coral larvae: implications for dispersal models. J Exp Mar Biol Ecol 409:324-330

* Tebben J, Tapiolas DM, Motti CA, Abrego D (2011) Induction of larval metamorphosis of the coral Acropora millepora by tetrabromopyrrole isolated from a Pseudoalteromonas bacterium. PLOS ONE 6:e19082

Tebben J, Guest JR, Sin TM, Steinberg PD, Harder T (2014) Corals like it waxed: paraffin-based antifouling technology enhances coral spat survival. PLOS ONE 9: e87545 
Tebben J, Motti CA, Siboni N, Tapiolas DM and others (2015) Chemical mediation of coral larval settlement by crustose coralline algae. Sci Rep 5:10803

* Toh TC, Ng CSL, Guest JR, Chou LM (2016) Grazers improve health of coral juveniles in ex situ mariculture. Aquaculture 415:288-293

Tomascik T, Sander F (1985) Effects of eutrophication on reef-building corals. I. Growth rate of the reef-building coral Montastrea annularis. Mar Biol 87:143-155

Tout J, Jeffries TC, Petrou K, Tyson GW and others (2015) Chemotaxis by natural populations of coral reef bacteria. ISME J 9:1764-1777

* Tran C, Hadfield MG (2011) Larvae of Pocillopora damicornis (Anthozoa) settle and metamorphose in response to surface-biofilm bacteria. Mar Ecol Prog Ser 433:85-96

Trapon ML, Pratchett MS, Hoey AS, Baird AH (2013) Influence of fish grazing and sedimentation on the early postsettlement survival of the tabular coral Acropora cytherea. Coral Reefs 32:1051-1059

* Tremblay P, Grover R, Maguer JF, Hoogenboom M, FerrierPagès C (2014) Carbon translocation from symbiont to host depends on irradiance and food availability in the tropical coral Stylophora pistillata. Coral Reefs 33:1-13

*Underwood JN, Smith LD, Van Oppen MJH, Gilmour JP (2007) Multiple scales of genetic connectivity in a brooding coral on isolated reefs following catastrophic bleaching. Mol Ecol 16:771-784

*van Oppen MJH, Oliver J, Putnam H, Gates R (2015) Building coral reef resilience through assisted evolution. Proc Natl Acad Sci USA 112:2307-2313

van Oppen MJH, Gates RD, Blackall LL, Cantin N and others (2017) Shifting paradigms in restoration of the world's coral reefs. Glob Change Biol 23:3437-3448

*Van Veghel MLJ, Bak RPM (1994) Reproductive characteristics of the polymorphic Caribbean reef building coral Montastrea annularis. III. Reproduction in damaged and regenerating colonies. Mar Ecol Prog Ser 109:229-233

* van Woesik R (2010) Calm before the spawn: global coral spawning patterns are explained by regional wind fields. Proc R Soc B 277:715-722

* van Woesik R, Lacharmoise F, Köksal S (2006) Annual cycles of solar insolation predict spawning times of Caribbean corals. Ecol Lett 9:390-398

*Vargas-Ángel B, Colley SB, Hoke SM, Thomas JD (2006) The reproductive seasonality and gametogenic cycle of Acropora cervicornis off Broward County, Florida, USA. Coral Reefs 25:110-122

Vermeij MJA (2006) Early life-history dynamics of Caribbean coral species on artificial substratum: the importance of competition, growth and variation in life-history strategy. Coral Reefs 25:59-71

*VVermeij MJA, Sandin SA (2008) Density-dependent settlement and mortality structure the earliest life phases of a coral population. Ecology 89:1994-2004

V Vermeij MJA, Sampayo E, Bröker K, Bak RPM (2003) Variation in planulae release of closely related coral species. Mar Ecol Prog Ser 247:75-84

Vermeij MJA, Sampayo E, Broker K, Bak RPM (2004) The reproductive biology of closely related coral species: gametogenesis in Madracis from the southern Caribbean. Coral Reefs 23:206-214

* Vermeij MJA, Marhaver KL, Huijbers CM, Nagelkerken I, Simpson SD (2010) Coral larvae move toward reef sounds. PLOS ONE 5:e10660
Veron JV (2000) Corals of the world. Australian Institute of Marine Science, Townsville, QLD

*Villanueva RD, Baria MVB, dela Cruz DW (2013) Effects of grazing by herbivorous gastropod (Trochus niloticus) on the survivorship of cultured coral spat. Zool Stud 52:44

* Vize PD (2006) Deepwater broadcast spawning by Montastraea cavernosa, Montastraea franksi, and Diploria strigosa at the Flower Garden Banks, Gulf of Mexico. Coral Reefs 25:169-171

*Wallace CC (1985) Reproduction, recruitment and fragmentation in nine sympatric species of the coral genus Acropora. Mar Biol 88:217-233

WWard S (1995) The effect of damage on the growth, reproduction and storage of lipids in the scleractinian coral Pocillopora damicornis (Linnaeus). J Exp Mar Biol Ecol 187:193-206

* Ward S, Harrison P (2000) Changes in gametogenesis and fecundity of acroporid corals that were exposed to elevated nitrogen and phosphorus during the ENCORE experiment. J Exp Mar Biol Ecol 246:179-221

Warner PA, Willis BL, van Oppen MJH (2016) Sperm dispersal distances estimated by parentage analysis in a brooding scleractinian coral. Mol Ecol 25:1398-1415

Webster NS, Reusch TBH (2017) Microbial contributions to the persistence of coral reefs. ISME J 11:2167

* Webster NS, Smith LD, Heyward AJ, Watts JEM, Webb RI, Blackall LL, Negri AP (2004) Metamorphosis of a scleractinian coral in response to microbial biofilms. Appl Environ Microbiol 70:1213-1221

*Webster NS, Uthicke S, Botté ES, Flores F, Negri AP (2013) Ocean acidification reduces induction of coral settlement by crustose coralline algae. Glob Change Biol 19:303-315

Whalan S, Abdul Wahab MA, Sprungala S, Poole AJ, de Nys R (2015) Larval settlement: the role of surface topography for sessile coral reef invertebrates. PLOS ONE 10: e0117675

Wilkinson C (2008) Status of coral reefs of the world: 2008. Global Coral Reef Monitoring Network and Reef and Rainforest Research Centre, Townsville, QLD

Willis BL, Babcock RC, Harrison PL, Oliver JK, Wallace CC (1985) Patterns in the mass spawning of corals on the Great Barrier Reef from 1981 to 1984. In: Gabrie C, Salvat B (eds) Proc 5th Int Coral Reef Congress, Vol 4. International Society for Reef Studies, Tahiti, p 343-348

Wilson ACC, Grosberg RK (2004) Ontogenetic shifts in fusion-rejection thresholds in a colonial marine hydrozoan, Hydractinia symbiolongicarpus. Behav Ecol Sociobiol 57:40-49

*Wilson J, Harrison P (2005) Post-settlement mortality and growth of newly settled reef corals in a subtropical environment. Coral Reefs 24:418-421

Wolanski E, Hamner WM (1988) Topographically controlled fronts in the ocean and their biological influence. Science 241:177-181

*Yamashita H, Suzuki G, Hayashibara T, Koike K (2013) Acropora recruits harbor 'rare' Symbiodinium in the environmental pool. Coral Reefs 32:355-366

*Yamashita H, Suzuki G, Kai S, Hayashibara T, Koike K (2014) Establishment of coral-algal symbiosis requires attraction and selection. PLOS ONE 9:e97003

Y Yamashita H, Suzuki G, Shinzato C, Jimbo M, Koike K (2018) Symbiosis process between Acropora larvae and Symbiodinium differs even among closely related Symbiodinium types. Mar Ecol Prog Ser 592:119-128 
Yellowlees D, Rees TAV, Leggat W (2008) Metabolic interactions between algal symbionts and invertebrate hosts. Plant Cell Environ 31:679-694

Yorifuji M, Harii S, Nakamura R, Fudo M (2017) Shift of symbiont communities in Acropora tenuis juveniles under heat stress. PeerJ 5:e4055

Young CM (1995) Behavior and locomotion during the dispersal phase of larval life. In: McEdward LR (ed) Ecology of marine invertebrate larvae. CRC Press, Boca Raton, FL, p 249-278

Young CN, Schopmeyer SA, Lirman D (2012) A review of

Editorial responsibility: Tim McClanahan, Mombasa, Kenya reef restoration and coral propagation using the threatened genus Acropora in the Caribbean and Western Atlantic. Bull Mar Sci 88:1075-1098

K Zakai D, Levy O, Chadwick-Furman NE (2000) Experimental fragmentation reduces sexual reproductive output by the reef-building coral Pocillopora damicornis. Coral Reefs 19:185-188

Zakai D, Dubinsky Z, Avishai A, Caaras T, Chadwick NE (2006) Lunar periodicity of planula release in the reefbuilding coral Stylophora pistillata. Mar Ecol Prog Ser 311:93-102

Submitted: April 8, 2019; Accepted: November 25, 2019 Proofs received from author(s): January 21, 2020 